\title{
Price and profit decisions in manufacturer-led dual-channel supply chain configurations
}

\author{
Umangi Pathak $^{\mathrm{a}^{*}}$, Ravi Kant ${ }^{\mathrm{a}}$ and Ravi Shankar ${ }^{\mathrm{b}}$
}

${ }^{a}$ Sardar Vallabhbhai National Institute of Technology, India

${ }^{b}$ Indian Institute of Technology Delhi, India

CHRONICLE ABSTRACT

\begin{tabular}{l} 
Article history: \\
Received September 252019 \\
Received in Revised Format \\
December 282019 \\
Accepted December 312019 \\
Available online \\
January 2 2020 \\
\hline Keywords: \\
Dual-supply chain \\
E-Commerce \\
Cooperative advertisement \\
Lead time \\
Free-riding
\end{tabular}

\section{Introduction}

Rise in digitalization, improved logistic infrastructures, increased fuel cost and development of etechnologies make a significant change in customers' consumption, purchase pattern and their preferences (Pu et al., 2017). Moreover in today's competitive environment and busy life, firms strongly need adoption of a business strategy which can help to get bigger market exposure with a controlled price, less inventory and inferior entry barriers (Choi, 2003). To resolve these issues, companies such as IBM, Dell and Apple have adopted e-business practices and obtained a noticeable change in their demand and profit (Matsui, 2016). Nonetheless, adoption of e-channels at the cost of eliminating retail practices is not a good decision because with the customer's viewpoint retail market is the most trustworthy, simple and convenient mode of purchase (Mahar et al., 2009). Real visualization, demonstration of products, in hand quality assurance, no waiting time, bargaining power of customer, service, repair at near premises and requisite of the customized product make retail market alive and compete to the e-tail market at each stage (Wang \& Ji, 2010). As a result, manufacturers are more

* Corresponding author Tel. :+918460801123

E-mail: um18119190@gmail.com (U. Pathak)

2020 Growing Science Ltd.

doi: $10.5267 /$ j.. jiec.2020.1.002

\begin{abstract}
In the world of digitization, e-commerce practices has become more popular and attracts manufacturers to combine their traditional retail channel with an e-channel. To add some salient for manufacturer-led dual-channel supply chain configurations; namely Vertically Integrated Dual-Supply Chain (VID-SC), Decentralized Dual-channel Supply Chain (DD-SC), Partially Integrate Dual-Supply Chain (PID-SC) and Horizontally Integrated Dual-Supply Chain (HIDcooperative advertisement, delivery lead time and free-riding on price and profit of manufacturer-led dual supply chain configurations. A linear programming for profit maximization is developed and backward induction method is used to find the optimum values of price and profit. A numerical analysis is performed to evaluate the effect of selected decision made to indicate the relationship between the selected decision parameters on optimum price. The best fit values of these decision parameters lead to the optimum price and the profit. The study helps to find the best fit value of the selected decision parameters for their specified dualto guide manufacturers and channel members as a dicine implementation of any strategy or policy.
\end{abstract}


inclined for adoption of dual-channel practices, where they can sell their commodities via two different channels, simultaneously. This era of digital and conventional marketing creates an emerging trend of dual supply chain as the most preferred fundamental of study for academicians and manufacturers. As manufacturer starts approaching customers via dual channels, this creates a threat to retailers and forms the myth of losing their market share. Several mathematical models have been developed to explain "What will happen to the retail market when e-business enters in to the market ?" and "What would be the effect on price and profit ?", (Ren et al., 2014; Yan et al., 2016). The research carried out by BrandonJones and Kauppi, (2018); Li and Huang, (2012) proves that adoption of e-channel along with retail channel reduces the wholesale price, increases customer span and improves service sharing for the retailers. This shows adoption of dual-channel is not a barrier; however it improves the overall profit of the supply chain members. To yield this benefit, many retailers have opened their own e-channel (i.e. Apple, Dell), while certain retailers start selling through third party e-sellers (i.e., Amazon) as well as several e-sellers open their retail stores to approach customers (i.e., Glossier, Boll \& Branch) (Galih, 2012). This scenario encourages manufacturers and researchers to explore the diversity in the field of dual supply chain. The adoption, management and handling of dual-channel are a complex practice.

\subsection{Research Agenda}

The assessment suggests that majority of research has been accomplished for centralized and decentralized dual-channel for a single decision parameter. This study adds new features in the existing studies by adding two new fundamentals. First is by introducing a bifurcation of manufacturer-led dualchannel configurations into four different channel configurations. Studies carried out by Chen et al., (2017); Modak and Kelle, (2019); Pu et al., (2017); Xiao and Shi, (2016); Yan et al., (2018); Zhao et al., (2016) and Zhou et al., (2018b) consider centralized and decentralized manufacturer-led, retailer-led and third party-led channel configurations. A part of these configurations in actual market condition the manufacturer-led dual-channel can be diverged into various four channel configurations as explained in detail in Table 1.

\section{Table 1}

Dual Channel Configurations

\begin{tabular}{|c|c|c|c|c|}
\hline Channel & Description & & Diagram & \\
\hline $\begin{array}{l}\text { Vertically } \\
\text { Integrated } \\
\text { Dual Supply } \\
\text { Chain } \\
\text { (VID-SC) }\end{array}$ & $\begin{array}{l}\text { VID-SC is the scenario in which the manufacturer owns his e- } \\
\text { channel and retail channel. Selling of Dell computers at Dell's } \\
\text { owned retail outlet and at e-channel handled by Intermediate } \\
\text { members are absent in this absent in this type of dual channel } \\
\text { structure, thus it is termed as a benchmark dual channel } \\
\text { structure. }\end{array}$ & $\begin{array}{l}\text { Intemet } \\
\text { Retailer }\end{array}$ & Manuf acturer & $\overbrace{\substack{\text { Traditional } \\
\text { Retailer }}}$ \\
\hline $\begin{array}{l}\text { Decentralized } \\
\text { Dual channel } \\
\text { Supply } \\
\text { Chain } \\
\text { (DD-SC) }\end{array}$ & $\begin{array}{l}\text { In DD-SC channel the manufacturer doesn't own any end } \\
\text { selling channel. He sales the products to an independent e- } \\
\text { tailer and retailer. Just like selling of NOKIA cell phone } \\
\text { through an independently handled Amazon (e-channel) and } \\
\text { retail store. }\end{array}$ & $\begin{array}{l}\text { Internet } \\
\text { Retailer }\end{array}$ & Manufacturer & $\begin{array}{c}\text { Traditional } \\
\text { Retailer }\end{array}$ \\
\hline $\begin{array}{l}\text { Partially } \\
\text { Integrate } \\
\text { Dual Supply } \\
\text { Chain } \\
\text { (PID-SC) }\end{array}$ & $\begin{array}{l}\text { In PID-SC channel the manufacturer drives an e-channel to } \\
\text { sell his products to the end users. Although to approach a large } \\
\text { market segment some amount of products are sold to the } \\
\text { retailer to reach the end users. Lenovo's dual channel strategy } \\
\text { is an example of PID-SC, as the e-channel is handled by } \\
\text { Lenovo itself but the retail selling is done by an independent } \\
\text { retailer. }\end{array}$ & $\begin{array}{l}\text { Intemet } \\
\text { Retailer }\end{array}$ & Manufacturer & $\begin{array}{l}\text { Traditional } \\
\text { Retailer }\end{array}$ \\
\hline $\begin{array}{l}\text { Horizontally } \\
\text { Integrated } \\
\text { Dual Supply } \\
\text { Chain } \\
\text { (HID-SC) }\end{array}$ & $\begin{array}{l}\text { Same as the DD-SC in HID-SC the manufacturer doesn't own } \\
\text { any end selling channel. In HID-SC, the products are sold to } \\
\text { an integrated channel having own retail as well as e-tail store. } \\
\text { Shoperstop is managing their SC activity by offering products } \\
\text { via their retail stores and e-tail shopping websites. }\end{array}$ & $\begin{array}{l}\text { Internet } \\
\text { Retailer }\end{array}$ & Manufacturer & $\begin{array}{l}\text { Traditional } \\
\text { Retailer }\end{array}$ \\
\hline
\end{tabular}

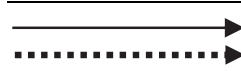

Channel Members are Integrated and work as a Unit

Channel Members are Isolated and work as an Individual 
The second fundamental is the consideration of more than one demand affecting parameter for the model development. To maximize the profit, one of the key ways for success is to boost the market demand. But for a particular product there is always a constant total market demand which is fulfilled by retailers and e-tailers. A channel member can only work to reduce customer switching from self-channel to the cross channel. This study measures advertisement, free-riding, and lead time as demand affecting parameters. The customer's switch form one channel to another is followed by advertisement or/and lead time or/and sales effort. If a channel offers wonderful advertisement policy but provides product after too long delivery time or doesn't provide any free-riding then demand at the particular channel decreases due to improper delivery adherence and absence of free-riding option, and vise a versa happens for all three parameters. The majority of study considers these three parameters individually in their models for centralized and decentralized case but to count them together in dual-channel configurations is a novel contribution of research.

The main objective of this study is to examine the effect of selected decision parameters (cooperative advertisement, delivery lead time and free-riding) on demand of dual supply chain on manufacturer-led dual-channel supply chain configurations (VID-SC, DD-SC, PID-SC and HID-SC). A linear program for profit maximization is developed and a backward induction method is used to find out the optimum values. A numerical data set, sensitivity analysis and interaction examination is also demonstrated in the study to recognize the effect of selected decision parameters on price and profit.

The rest of the paper is structured as follows. Literature review is explained in section 2. Section 3 covers assumptions and model development for all the four scenarios. Section 4 includes numerical results, sensitivity analysis and interaction plots. The summary of results and scope for future work are discussed in section 5 .

\section{Literature review}

This section summarizes the relevant literatures to support the developed model for dual supply chain. The study includes three decision parameters namely cooperative advertisement, delivery lead time and free-riding as a demand affecting parameters for the model development. Table 2 gives a brief analysis of mathematical models developed for centralized and decentralized dual-channel supply chain.

Table 2

A comparison of current model with existing dual supply chain models

\begin{tabular}{|c|c|c|c|c|c|}
\hline \multirow[b]{2}{*}{ Reference } & \multirow[b]{2}{*}{ Objectives } & \multicolumn{3}{|c|}{ Model Parameters } & \multirow[b]{2}{*}{ Channel Scenario } \\
\hline & & 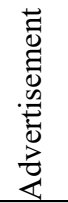 & 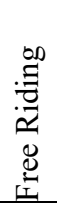 & 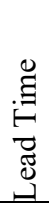 & \\
\hline Liu et al., (2013) & $\begin{array}{l}\text { Compare cooperative advertising for } \\
\text { traditional and dual channel }\end{array}$ & Yes & & & Decentralized \\
\hline Yan et al., (2006) & $\begin{array}{l}\text { Obtain equilibrium pricing and cooperative } \\
\text { advertising policies }\end{array}$ & Yes & & & Decentralized \\
\hline Chen, (2015) & $\begin{array}{l}\text { Evaluate the impact of cooperative advertising } \\
\text { mechanisms on channel conflict and pricing } \\
\text { schemes }\end{array}$ & Yes & & & - \\
\hline Kai, (2016) & $\begin{array}{l}\text { Measure influence of asymmetric demand } \\
\text { information on price discount and cooperative } \\
\text { advertisement }\end{array}$ & Yes & & & $\begin{array}{l}\text { Centralized and } \\
\text { Decentralized }\end{array}$ \\
\hline Xie et al., (2017) & $\begin{array}{l}\text { Analyze influence of advertisement revenue } \\
\text { sharing ratio on price and advertising } \\
\text { investment }\end{array}$ & Yes & & & $\begin{array}{l}\text { Centralized and } \\
\text { Decentralized }\end{array}$ \\
\hline
\end{tabular}


Table 2

A comparison of current model with existing dual supply chain models (Continued)

\begin{tabular}{|c|c|c|c|c|c|}
\hline \multirow[b]{2}{*}{ Reference } & \multirow[b]{2}{*}{ Objectives } & \multicolumn{3}{|c|}{ Model Parameters } & \multirow[b]{2}{*}{ Channel Scenario } \\
\hline & & 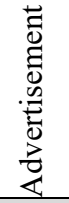 & 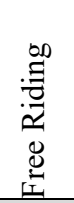 & 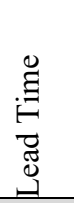 & \\
\hline Dan et al., (2014) & $\begin{array}{l}\text { Investigate impact of bidirectional free riding } \\
\text { and service competition on pricing decision }\end{array}$ & & Yes & & Decentralized \\
\hline He et al., (2016) & $\begin{array}{l}\text { Evaluate the impact of consumer free riding } \\
\text { on carbon emissions andon governmental e- } \\
\text { commerce tax }\end{array}$ & & Yes & & - \\
\hline $\begin{array}{l}\text { Shi and Ma, } \\
(2016)\end{array}$ & $\begin{array}{l}\text { Analyze influence of trust input, altruistic } \\
\text { tendency, learning abilities on free riding }\end{array}$ & & Yes & & $\begin{array}{l}\text { Centralized and } \\
\text { Decentralized }\end{array}$ \\
\hline Pu et al., (2017) & $\begin{array}{l}\text { Study the effects of free riding on sales effort, } \\
\text { demand and profit }\end{array}$ & & Yes & & $\begin{array}{l}\text { Centralized and } \\
\text { Decentralized }\end{array}$ \\
\hline $\begin{array}{l}\text { Yang et al., } \\
(2017)\end{array}$ & $\begin{array}{l}\text { Measure stock out-based and lead time based } \\
\text { consumer switching behavior to examine the } \\
\text { order quantity and inventory decision }\end{array}$ & & & Yes & $\begin{array}{l}\text { Centralized and } \\
\text { Decentralized }\end{array}$ \\
\hline Xu et al., (2012) & $\begin{array}{l}\text { Investigate effect of price and delivery lead } \\
\text { time }\end{array}$ & & & Yes & $\begin{array}{l}\text { Centralized and } \\
\text { Decentralized }\end{array}$ \\
\hline Hua et al., (2010) & $\begin{array}{l}\text { Examined the optimal decisions for delivery } \\
\text { lead time and prices for }\end{array}$ & & & Yes & $\begin{array}{l}\text { Centralized and } \\
\text { Decentralized }\end{array}$ \\
\hline $\begin{array}{l}\text { Modak and } \\
\text { (Kelle, 2019) }\end{array}$ & $\begin{array}{l}\text { Analyze effect of delivery lead time and } \\
\text { customers' channel preference for price } \\
\text { decision }\end{array}$ & & & Yes & Centralized \\
\hline Saha et al., (2018) & $\begin{array}{l}\text { Characterize effect on price due to delivery } \\
\text { time sensitive demand/customer }\end{array}$ & & & Yes & Decentralized \\
\hline Proposed model & $\begin{array}{l}\text { Investigates the effect of decision parameters } \\
\text { on demand, price and profit }\end{array}$ & Yes & Yes & Yes & $\begin{array}{l}\text { Centralized, Decentralized, } \\
\text { Partially and Horizontally } \\
\text { Integrated }\end{array}$ \\
\hline
\end{tabular}

\subsection{Cooperative Advertisement}

An accurate level of advertisement creates awareness and helps to attract customers, which finally improves the demand but, an effective advertisement strategy consumes certain profit share of the organization (Bergen \& John, 1997). The advertisement in dual supply chain can be done by selling member (retail and e-tail) separately or jointly. The research prepared by Che, (2015) and Yan et al. (2006) says a when both the end selling members come together they can serve as many customers as possible with the least advertisement cost, effort and conflict. Yan et al. (2006) studied the impact of cooperative advertising on the demand and profit, to consider different dual supply channel partners under different market structures based on product compatibilities. Chen (2015) evaluated the impact of price discount schemes along with cooperative advertising to analyse a relationship between cooperative cost and effort share between dual-channel bodies for decision making practices. The result revealed that a cooperative advertisement policy is always superior to a non-cooperative policy for profit improvement. Xie et al. (2017) examined the influence of optimal price, wholesale price and advertising investment on revenue sharing ratio for dual channels. Guo and Ma, (2018) analysed the impact of cooperative advertising on price and profit to observe how cooperative advertising can benefit manufacturer and retailer. An adjustment mechanism is explained by the researchers to analyse the exponential advertising response under dynamic process and inaccurate profit information. The research carried out by Bergen and John (1997), Chen (2015), Chutani and Sethi (2018), Karray et al. (2017), Kundu and Chakrabarti, (2018), Xie et al. (2017), Yan and Pei (2015) and Zhou et al. (2018) for dual supply chain concludes that a cooperative advertisement strategy helps both the channel member but they have pre-assumes a 
symmetric demand function without the demand fluctuation. To overcome this barrier, Kai (2016) developed a model for cooperative advertisement and explained about, how advertising decisions change with asymmetric demand information and price discounts.

\subsection{Free-riding}

Free-riding in dual supply chain happens when one channel member (retail) is putting efforts for the customer service activities like demonstration, physical testing etc. and his activities and efforts helps another (e-tail) channel member for the final sale of their commodity (Pu et al., 2017). When the product is available at two different channels customer will choose the retail store to physically test the product and will purchase it from the e-channel at lower cost. This phenomenon reduces selling and profit at retail stores. Hence sometimes retailers refuse to keep such products at their stores or refuse to become a part of free-riding selling pattern (Dan et al., 2014; Zhou et al., 2018). As the free-riding convenience to the customer reduces the overall demand also get shirked, to overcome this barrier, manufacturer and echannel members share a specific amount of profit with retailer to make the product available at the retail store for the free-riding. Dan et al. (2014) examined the impacts of bi-directional free-riding to develop a decision making model for selecting most favourable service levels under different dual supply chains scenario. He et al. (2016) analysed an impact of consumer free-riding on carbon emissions and governmental e-commerce tax for a dual-channel closed loop supply chain. Pu et al. (2017) developed an effective cost-sharing contract to encourage the offline stores to spend more on the sales effort and free-riding and proposed a cost sharing contract to coordinate a decentralized channel to achieve beneficial results.

\subsection{Delivery Lead Time}

Delivery lead time refers to a time period between placing an order to receiving the product. It includes time for order placing, handling, collecting, packing and transporting. The longer customers waiting time towards products and services leads to demand degradation (Saha et al., 2018). Many researchers have put their efforts to analyse adverse effect of longer lead time on demand, price and inventory (Modak and Kelle, 2019; Saha et al., 2018; Yang et al., 2017). Kay Yut Chen, (2008) analysed consumer's channel choice by their willingness to wait, product availability concerns and relative convenience for shopping in dual channels. The study identified optimal dual-channel strategies to choose between a direct channel and a retail channel if manufacturer is already selling products through one of these channels. Hua et al. (2010) investigated the effect of delivery lead time on customer's e-channel acceptance and explained how delivery lead time influences manufacturer's and the retailer's pricing strategies and profits. Xu et al. (2012) examined how delivery lead time influence the channel design and enlightened various pricing strategies under diverse form of ownership for different dual-channel structures. Yang et al. (2017) studied customer's stock-out-based and lead time-based switching. Their obtained result explore about two approaches, the manufacturer adopts a "slow down deliver later" approach for the less delivery lead time sensitive customers and "stay fast and brag about better services" as customers become more sensitive to delivery lead time. Modak and Kelle (2019) evaluated the effect of delivery lead time and customers' channel preference to develop a profit maximization model. The optimal online delivery lead time in decentralized channel is less than in centralized channel.

\section{The Model}

The following are assumptions to make the model more accurate and reliable for numerical simplicity.

Assumptions for model formulation: (Chiang et al., 2003; Mcguire et al., 2008; Yoo \& Lee, 2011)

a) The model is developed for deterministic and linear demand without shortage.

b) Carrying, holding, transporting and other overhead costs are constant. 
c) Demand and price fluctuation due to environmental effect is neglected. Discounts or complementary privileges are not allowed.

d) No constraint for space, capital and capacity.

e) The product is manufactured by a single manufacturer thus quality, warranty, specification is considered as a constant parameter and hence they don't affect the demand value.

f) Manufacturer acts as Stackelberg leader, retail and e-channels acts as a Stackelberg follower.

g) The game between two independent retailers or e-tailers is purely Bertrand-Nash.

h) Supply chain members are risk natural and aimed to maximize their individual profit. But if channel members are horizontally integrated, the pricing decision is made to maximize the joint profits.

The list of following nomenclature is used for the convenience of the model formulation.

\section{Parameters}

$\rho=$ Consumer's Preference for E-tail Channel

1 - $\rho=$ Consumer's Preference for Retail Channel

$a=$ Potential Demand (independent of price, advertisement, time and free-riding)

$\beta_{j}=$ Cross-Price Sensitivity $(\mathrm{j}=1,2 ; 1=$ retailer to e-tailer, $2=\mathrm{e}$-tailer to retailer $)$

$\alpha_{j}=$ Self-Price Sensitivity

$X=$ Manufacturer's Participation in Total Advertisement

$1-X=$ Retailer's Participation in Total Advertisement

$\tau=$ Free-Riding Ratio

$\Psi=$ Delivery Time Sensitive Customers

$\gamma=$ Time based switching of Demand

$C_{i}=$ Carrying/ Holding cost

$m / t=$ Unit Delivery Cost

$t=$ Delivery Lead Time for One Unit

$A=$ Co-Operative Advertising Expenditure

$K=$ Effect of Co-Operative Advertisement on Sales

$D_{i}=$ Forecasted demand $(i=m$ - manufacturer, $r$-retailer, $d$ - e-tailer $)$

\section{Decision Variables}

$W_{i}=$ Wholesale Price offered by manufacturer per unit

$P i=$ Selling price per product per unit

$\Pi_{i}=$ Profit of earned

\subsection{Model formulation}

In present study, it is assumed that demand is a deterministic linear function of five parameters; channel preference, self and cross-price, total advertisement cost and effort, lead time and free- riding level; and it is represented as $D=f(\rho, P, A, t, S)$ (Batarfi et al., 2017, 2016). 
The total market demand $\mathrm{D}$ is satisfied by $D=D_{r}+D_{d}$ where $D_{r}=(1-\rho) a-\alpha_{1} P_{r}+\beta_{1} P_{d}+K \sqrt{A}+$ $\gamma * t+(1-\tau) S$ and $D_{d}=\rho a+-\alpha_{2} P_{d}+\beta_{2} P_{r}+K \sqrt{A}-\psi * t+\tau S$.

The demand gets switched to either channel due to various factors. The first factor is $\rho$. The term $\rho$ depends on population density near the retail outlet, trust on channel, bargaining power, geographical area, internet facility and literacy, product category etc., $0 \leq \rho \leq 1$ (Mukhopadhyay and Setoputro, 2004). The second factor that influences the demand self-price $\left(\alpha_{\mathrm{i}}\right)$ and cross-price $\left(\beta_{\mathrm{i}}\right)$ elastic coefficients, $\left(\alpha_{i}\right.$ $>\beta_{i}$ for $\left.i=1,2\right)$ (Chen et al., 2017; Giri et al., 2017; Huang et al., 2015, 2012). To promote the product channel members spent some amount of profit in advertisement cost and the cost allied with total advertisement is expressed as "A" paid by only end selling members. From total expenditure A, $X A$ amount of advertisement cost is paid by e-tail seller and $(1-X) A$ amount of cost is paid by retail seller. Where, $\mathrm{X}(0 \leq \mathrm{X} \leq 1)$ is an ordinance of cooperative advertisement. Another factor is delivery lead time. As e-tailer's offered delivery time is increased by one unit, $\Psi$ units of customers/demand are loss by the e-tailer, out of which $\gamma$ units of customers will switch to retail channel for a quicker delivery option. Here, $\Psi \neq \gamma$ and $\Psi>\gamma$, few customers switch to different product, postpone/refuse to buy or purchase it from competitor's channel (Hua et al., 2010). At this stage $\Psi-\gamma$ units of demand is lost by the manufacturer. The next factor to influence the demand is $\tau$, indicating a level of free-riding, as value of $\tau$ changes the demand at the retail channel is changed by $(1-\tau) S$ units, and demand at e-channel changes by $\tau S$ units (Pu et al., 2017). Where $S$ defines the unit cost of sales efforts. The portion of switched demand from retailer to e-tailer, due to price difference at both channels is expressed as $D_{f}=$ $\tau\left[\frac{\beta_{1}+\beta_{2}}{2}\right] \times\left(P_{r}-P_{d}\right)$.

The cumulative of holding, inventory and shipping charges paid by retailer and e-tailer are $C_{r}$ and $C_{d}$ respectively. The effort associated with holding, inventory and shipping for both the channels are different. Therefore, the cost is also different. The consumer can buy a product from retail channel at $P_{r}$ price or form e-channel at $P_{d}$ price (which satisfies $P_{r}>W_{r}+C_{r}, P_{d}>W_{d}+C_{r}$ ).

\subsection{Research Methodology}

In this study, the logic of backward induction game theory is applied in a Stackelberg game. The manufacturer is so-called as a Stackelberg Leader, and the retailer and e-tailer are called as a Follower. Moreover, a bordered Hessian is used for the second-derivative test in certain constrained optimization problems. Flowing steps are followed to solve the model:

1. The value of last decision parameters selling price as $P_{r}, P_{d}$ are solved using first order derivative test. And their concavity with respect to profit function a second-order partial derivative test using Hessian matrix is analysed.

2. Substituting the optimum values of selling price in profit equations. The first move of deciding wholesale price for the channel members $\left(\mathrm{W}_{\mathrm{r}}, \mathrm{W}_{\mathrm{d}}\right)$ are resolved, by similar first order derivative test and Hessian matrix properties.

3. All the obtained optimum values of decision parameters are placed in profit equation to find the profit.

\subsubsection{Case 1. Vertically Integrated Dual-channel Supply Chain(VID-SC)}

The manufacturer acts as a Strackelberg leader and decides $P_{r}$ and $P_{d}$ to maximize $\pi_{m(V I D)}$ and the profit is defined as:

$$
\operatorname{Max} \pi_{m(V I D)}=\left[\left(P_{r}-C_{r}\right) D_{r}+\left(P_{d}-C_{d}-(m / t)\right) D_{d}-A-\left(C_{r} * D_{f}\right)\right]
$$

The model is solved using the steps explained above in research methodology section and the proofs are given in Appendix A. 


$$
\begin{aligned}
P_{r}{ }^{*}=-\left(4 S \alpha_{2}\right. & t+2 \alpha_{2} m\left(\beta_{1}-\beta_{2}\right)+4 \alpha_{1} \alpha_{2} t-2 C_{r} \beta_{1}{ }^{2} t-2 \Psi t^{2}\left(\beta_{1}+\beta_{2}\right)+4 \alpha_{2} \gamma t^{2} \\
& -4 \alpha_{1} \alpha_{2} \rho t+2 \alpha_{1} \rho t\left(\beta_{1}+\beta_{2}\right)+4 \sqrt{A} K \alpha_{2} t+C_{r} t \tau\left(\beta_{1}{ }^{2}+\beta_{2}{ }^{2}\right) \\
& +4 C_{r} \alpha_{1} \alpha_{2}+2 C_{d} \alpha_{2} t\left(\beta_{1}-\beta_{2}\right)-2 C_{r} \beta_{1} \beta_{2} t-4 S \alpha_{2} t \tau+2 S t \tau\left(\beta_{1}+\beta_{2}\right) \\
& -2 C_{r} \alpha_{2} t \tau\left(\beta_{1}+\beta_{2}\right)+2 C_{r} \beta_{1} \beta_{1} t \tau-4 \sqrt{A} K \alpha_{2} \rho t \\
& +2 \sqrt{A} K \rho t\left(\beta_{1}+\beta_{2}\right) /\left(2 t\left(\beta_{1}{ }^{2}+2 \beta_{1} \beta_{2}+\beta_{2}{ }^{2}-4 \alpha_{1} \alpha_{2}\right)\right) \\
P_{d}{ }^{*}=-\left(2 S \beta_{1}\right. & t-2 \beta_{2}{ }^{2} m+2 S \beta_{2} t+4 \alpha_{1} \alpha_{2} m-2 \beta_{1} \beta_{2} m+2 a\left(\beta_{1}+\beta_{2}\right) t-2 C_{d} \beta_{2}{ }^{2} t \\
& -4 \alpha_{1} \Psi t^{2}+2 \gamma t^{2}\left(\beta_{1}+\beta_{2}\right)+4 a \alpha_{1} \rho t-2 a \rho t\left(\beta_{1}+\beta_{2}\right) \\
& +2 \sqrt{A} t\left(\beta_{1}+\beta_{2}\right)-C_{r} t \tau\left(\beta_{1}{ }^{2}+\beta_{2}{ }^{2}\right)+4 C_{d} \alpha_{1} \alpha_{2} t-2 C_{r} \alpha_{1}\left(\beta_{1}-\beta_{2}\right) t \\
& -2 C_{d} \beta_{1} \beta_{2} t+4 S \alpha_{1} t \tau-2 S\left(\beta_{1}+\beta_{2}\right) t \tau+2 C_{r} \alpha_{1}\left(\beta_{1}+\beta_{2}\right) t \tau \\
& -2 C_{r} \beta_{1} \beta_{2} t \tau+4 \sqrt{A} K \alpha_{1} \rho t-2 \sqrt{A} K \rho t\left(\beta_{1}+\beta_{2}\right) /\left(2 t \left(\beta_{1}{ }^{2}+2 \beta_{1} \beta_{2}\right.\right. \\
+ & \left.\left.\beta_{2}{ }^{2}-4 \alpha_{1} \alpha_{2}\right)\right)
\end{aligned}
$$

Substituting values of $P_{r}{ }^{*}$ and $P_{d}{ }^{*}$ in Eq. (1) gives the maximum value of profit earned by the manufacturer in VID-SC as $\pi_{m(V I D)}{ }^{*}$.

\subsubsection{Case 2. Decentralized Dual-channel Supply Chain (DD-SC)}

Here, the manufacturer act as a Stackelberg leader and sets wholesale price first for retailer $\left(\mathrm{W}_{\mathrm{r}}\right)$ and etailer $\left(\mathrm{W}_{\mathrm{d}}\right)$ to maximize his profit $\pi_{m(D D)}$. In respond to that retailer and e-tailer act as a Stackelberg follower to set their selling price $P_{r}$ and $P_{d}$ to maximize their individual profits as $\pi_{r(D D)}$ and $\pi_{d(D D)}$ respectively. Their corresponding profit equations are given below.

$$
\begin{aligned}
& \operatorname{Max} \pi_{m(D D)}=\left(W_{r}\right) D_{r}+\left(W_{d}\right) D_{d} \\
& \operatorname{Max} \pi_{r(D D)}=\left(P_{r}-W_{r}-C_{r}\right) D_{r}-(1-X) A-\left(C_{r} * D_{f}\right) \\
& \operatorname{Max} \pi_{d(D D)}=\left(P_{d}-W_{d}-C_{d}-(m / t)\right) D_{d}-X A
\end{aligned}
$$

The above explained steps are followed to find out the optimum selling price for retailer and e-tailer in DD-SC as:

$$
\begin{aligned}
P_{r}^{*}=\left(2 S \alpha_{2} t\right. & +\alpha_{2} \beta_{1} m+2 a \alpha_{2} t-\beta_{1} \varphi t^{2}-2 \alpha_{2} \gamma t^{2}-2 a \alpha_{2} \rho t+a \beta_{1} \rho t+2 \sqrt{A} K \alpha_{2} t \\
& +2 C_{r} \alpha_{1} \alpha_{2} t+C_{d} \alpha_{2} \beta_{1} t+2 W_{r} \alpha_{1} \alpha_{2} t+W_{d} \alpha_{2} \beta_{1} t-2 S \alpha_{2} t \tau+S \beta_{1} t \tau \\
& \left.-C_{r} \alpha_{2} \beta_{1} t \tau-C_{r} \alpha_{2} \beta_{2} t \tau-2 \sqrt{A} K \alpha_{2} \rho t+\sqrt{A} K \beta_{1} \rho t\right) /\left(t\left(4 \alpha_{1} \alpha_{2}-\beta_{1} \beta_{2}\right)\right) \\
P_{d}{ }^{*}=\left(2 S \beta_{2} t\right. & +4 \alpha_{1} \alpha_{2} m+2 a \beta_{2} t-4 \alpha_{1} \Psi t^{2}+2 \beta_{2} \gamma t^{2}+4 a \alpha_{1} \rho t-2 a \beta_{2} \rho t \\
+ & 2 \sqrt{A} K \beta_{2} t-C_{r} \beta_{2}{ }^{2} t \tau+4 C_{d} C d \alpha_{1} \alpha_{2} t+2 C_{r} \alpha_{1} \beta_{2} t+4 W_{d} \alpha_{1} \alpha_{2} t \\
& +2 W_{r} \alpha_{1} \beta_{2} t+4 S \alpha_{1} t \tau-2 S \beta_{2} t \tau-C_{r} \beta_{1} \beta_{2} t \tau+4 \sqrt{A} K \alpha_{1} \rho t \\
& \left.-2 \sqrt{A} K \beta_{2} \rho t\right) /\left(2 t\left(4 \alpha_{1} \alpha_{2}-\beta_{1} \beta_{2}\right)\right)
\end{aligned}
$$

Appendix B provides the supporting data for model solution. (Considering length of paper $\mathrm{W}_{\mathrm{r}}$ * and $\mathrm{W}_{\mathrm{d}}$ * values are not given in the paper but they are considered for numerical studies).

\subsubsection{Case 3. Partially Integrated Dual-Channel Supply Chain (PID-SC)}

First manufacturer as a Steckleberg leader decides his online selling price $P_{d}$ and retail wholesale price $W_{r}$, based on his decision retailer as a Steckleberg follower decides his retail selling price $P_{r}$, and the respective profit eqs. are given as: 


$$
\begin{aligned}
& \operatorname{Max} \pi_{m(P I D)}=\left(W_{r}\right) D_{r}+\left(P_{d}-W_{d}-C_{d}-(m / t)\right) D_{d}-X A \\
& \operatorname{Max} \pi_{r(P I D)}=\left(P_{r}-W_{r}-C_{r}\right) D_{r}-(1-X) A-\left(C_{r} * D_{f}\right)
\end{aligned}
$$

Solving above equations,

$$
\begin{aligned}
P_{d}{ }^{*}=\left(2 S \beta_{2}\right. & +4 \alpha_{1} \alpha_{2} m+2 a \beta_{2} t-4 \alpha_{1} \Psi t^{2}+2 \beta_{2} \gamma t^{2}+4 a \alpha_{1} \rho t-2 a \beta_{2} \rho t \\
& +2 \sqrt{A} K \beta_{2} t-C_{r} \beta_{2}{ }^{2} t \tau+4 C_{d} \alpha_{1} \alpha_{2} t+2 C_{r} \alpha_{1} \beta_{2} t+4 W_{r} \alpha_{1} \beta_{1} t \\
& +2 W_{r} \alpha_{1} \beta_{2} t+4 S \alpha_{1} t \tau-2 S \beta_{2} t \tau-C_{r} \beta_{1} \beta_{2} t \tau+4 \sqrt{A} K \alpha_{1} \rho t \\
& \left.-2 \sqrt{A} K \beta_{2} \rho t\right) /\left(2 t\left(4 \alpha_{1} \alpha_{2}-\beta_{1} \beta_{2}\right)\right) \\
P_{r}{ }^{*}=\left(2 S \alpha_{2} t\right. & +\alpha_{2} \beta_{1} m+2 a \alpha_{2} t+W_{r} \beta_{1}{ }^{2} t-\beta_{1} \Psi t^{2}+2 \alpha_{2} \gamma t^{2}-2 a \alpha_{2} \rho t \\
& +a \beta_{1} \rho t+2 \sqrt{A} K \alpha_{2} t+2 C_{r} \alpha_{1} \alpha_{2} t+C_{d} \alpha_{2} \beta_{1} t+2 W_{r} \alpha_{1} \alpha_{2} t \\
& -2 S \alpha_{2} t \tau+S \beta_{1} t \tau-C_{r} \alpha_{2} \beta_{1} t \tau-C_{r} \alpha_{2} \beta_{2} t \tau-2 \sqrt{A} K \alpha_{2} \rho t \\
& \left.\left.+\sqrt{A} K \beta_{1} \rho t\right) /\left(t\left(4 \alpha_{1} \alpha_{2}-\beta_{1} \beta_{2}\right)\right)+\sqrt{A} K \beta_{1} \rho t\right) /\left(t\left(4 \alpha_{1} \alpha_{2}-\beta_{1} \beta_{2}\right)\right)
\end{aligned}
$$

Substituting values of $W_{r}{ }^{*}, P_{r}{ }^{*}$ and $P_{d}{ }^{*}$ in Eq. (9) and Eq. (10) gives the maximum value of profit earned by the manufacturer and retailer PID-SC see Appendix C.

Case 4. Horizontally Integrated Dual-channel (HID-SC)

In HID-SC manufacturer sells his products to a single body at a wholesale price $W=W_{r}=W_{d}$ and does not get involved in end selling practise. The manufacturer first act as Stackelberg leader and decides wholesale price $W$ after that an integrated body decides their selling price $P_{r}$ and $P_{d}$ for retail and echannel respectively. Their corresponding profit equations are given as below.

$$
\begin{gathered}
\operatorname{Max}_{m(H I D)}=\left(D_{r}+D_{d}\right) W \\
\operatorname{Max} \pi_{r / d(H I D)}=\left(P_{r}-W-C_{r}\right) D_{r}+\left(P_{d}-W-C_{d}-(\mathrm{m} / t)\right) D_{d}-A
\end{gathered}
$$

Using backward induction method steps as explained above section.

$$
\begin{aligned}
P_{r}{ }^{*}=-\left(2 S \alpha_{2}\right. & +\alpha_{2} m\left(\beta_{1}-\beta_{2}\right)+2 a \alpha_{2} t-C r \beta_{1}{ }^{2} t-W \beta_{1}{ }^{2} t-\left(\beta_{1}+\beta_{2}\right) \Psi t^{2} \\
& +2 \alpha_{2} \gamma t^{2}-2 a \alpha_{2} \rho t+a\left(\beta_{1}+\beta_{2}\right) \rho t+2 \sqrt{A} K \alpha_{2} t+2 C_{r} \alpha_{1} \alpha_{2} t \\
& +C_{d} \alpha_{2}\left(\beta_{1}-\beta_{2}\right) t-C_{r} \beta_{1} \beta_{2} t+2 W \alpha_{1} \alpha_{2} t+W \alpha_{2}\left(\beta_{1}-\beta_{2}\right) t-W \beta_{1} \beta_{2} t \\
& \left.-2 S \alpha_{2} t \tau+S\left(\beta_{1}+\beta_{2}\right) t \tau-2 \sqrt{A} K \alpha_{2} \rho t+\sqrt{A} K\left(\beta_{1}+\beta_{2}\right) \rho t\right) /\left(t \left(\beta_{1}{ }^{2}\right.\right. \\
& \left.\left.+2 \beta_{1} \beta_{2}+\beta_{2}{ }^{2}-4 \alpha_{1} \alpha_{2}\right)\right) \\
P_{d}{ }^{*}=\left(S \beta_{1} t\right. & -\beta_{2}{ }^{2} m+S \beta_{2} t+2 \alpha \alpha_{2} m-\beta_{1} \beta_{2} m+a \beta_{1} t+a \beta_{2} t-C_{d} \beta_{2}{ }^{2} t \\
& -W \beta_{2}{ }^{2} t-2 \alpha_{1} \Psi t^{2}+\left(\beta_{1}+\beta_{2}\right) \gamma t^{2}+2 a \alpha_{1} \rho t-a \rho t\left(\beta_{1}+\beta_{2}\right) \\
& +\sqrt{A} K\left(\beta_{1}+\beta_{2}\right) t+2 C_{d} \alpha_{1} \alpha_{2} t-C_{r} \alpha_{1}\left(\beta_{1}+\beta_{2}\right) t-C_{d} \beta_{1} \beta_{2} t \\
& +2 W \alpha_{1} \alpha_{2} t-W \alpha_{1}\left(\beta_{1}-\beta_{2}\right) t-W \beta_{1} \beta_{2} t+2 S \alpha_{1} t \tau-S\left(\beta_{1}+\beta_{2}\right) t \tau \\
& \left.+2 \sqrt{A} K \alpha_{1} \rho t-\sqrt{A} K\left(\beta_{1}+\beta_{2}\right) \rho t\right) /\left(t\left(\beta_{1}{ }^{2}+2 \beta_{1} \beta_{2}+\beta_{2}{ }^{2}-4 \alpha_{1} \alpha_{2}\right)\right)
\end{aligned}
$$

Appendix D provides the supporting data for model solution.

\section{Sensitivity analysis}

This section shows effect of selected decision parameters on demand, piece and profit by a numerical analysis. The demand affecting decision parameter is placed on $\mathrm{X}$-axis, selling price on primary $\mathrm{Y}$-axis and profit on secondary $\mathrm{Y}$-axis. The parameters for analysis are considered as follows: $C_{r}=20, C_{d}=30$; 
$A=10, S=30, a=500, \rho=0.5, m=25, K=6, X=0.5, \psi=5, \gamma=5, \alpha_{1}=6 ; \beta_{1}=0.8, \alpha_{2}=4, \beta_{2}=1.1, \tau=0.5$ and $t=5$. The value of numerical data set is taken based on assumption made in this study.

\subsection{Effect of cooperative advertisement level $(X)$}

Observation 1: $\frac{\partial D_{d}{ }^{*}}{\partial \sqrt{A}}>0$ and $\frac{\partial D_{r}{ }^{*}}{\partial \sqrt{A}}>0$, for $0<\rho<0.5 \frac{\partial D_{r}{ }^{*}}{\partial \sqrt{A}}>\frac{\partial D_{d}{ }^{*}}{\partial \sqrt{A}}$ and, for $0.5 \leq \rho<1 \frac{\partial D_{r}{ }^{*}}{\partial \sqrt{A}}<\frac{\partial D_{d}{ }^{*}}{\partial \sqrt{A}}$.

Observation 1 indicates, any rise in advertisement expenditure helps to improve the demand. This relation holds good for all channel configurations. But for certain products customers are having higher preference to buy from retail store than the e-store $(0<\rho<0.5)$, at this stage the rate of increase in demand at retail store is higher than the e-tail store, and vice a versa. Hence, the decision of advertisement expenditure should be taken after considering the customer's channel preference.

Observation 2: For all channel configurations $\frac{\partial P_{r}{ }^{*}}{\partial \sqrt{A}}>0$ and $\frac{\partial P_{d}{ }^{*}}{\partial \sqrt{A}}>0$ but, if $0<\rho<0.5$ then $\frac{\partial P_{r}{ }^{*}}{\partial \sqrt{A}}>\frac{\partial P_{d}{ }^{*}}{\partial \sqrt{A}}$ and if $0.5 \leq \rho<1$ then $\frac{\partial P_{r}{ }^{*}}{\partial \sqrt{A}}<\frac{\partial P_{d}{ }^{*}}{\partial \sqrt{A}}$.

Observation 2 implies a general phenomenon that product becomes more costly with the rise in advertisement expenditure. But, when the consumer prefers e-channel more $(0.5 \leq \rho<1)$, the rise in price with advertisement cost at e-channel is greater than that of the retail channel, and vice a versa. The more the channel loyal customer lesser the cost of advertisement and product become comparatively cheap. Along with this, for the advertisement cost optimization, there exists an optimum value of $\sqrt{A}^{*}$ (for which $\frac{\partial \pi^{*}}{\partial \sqrt{A}^{*}}=0$ ). In the case of cooperative advertisement both the channel members shares cost of advertisement. Here, from the total advertisement expenditure $\left(\sqrt{A}^{*}\right)$, e-tailer and retailer pays X and (1$\mathrm{X}$ ) fraction of amounts respectively. The effect of variation in $\mathrm{X}$ on price and profit for various channel structures are presented in Fig. 1 (a), (b), (c) and (d).

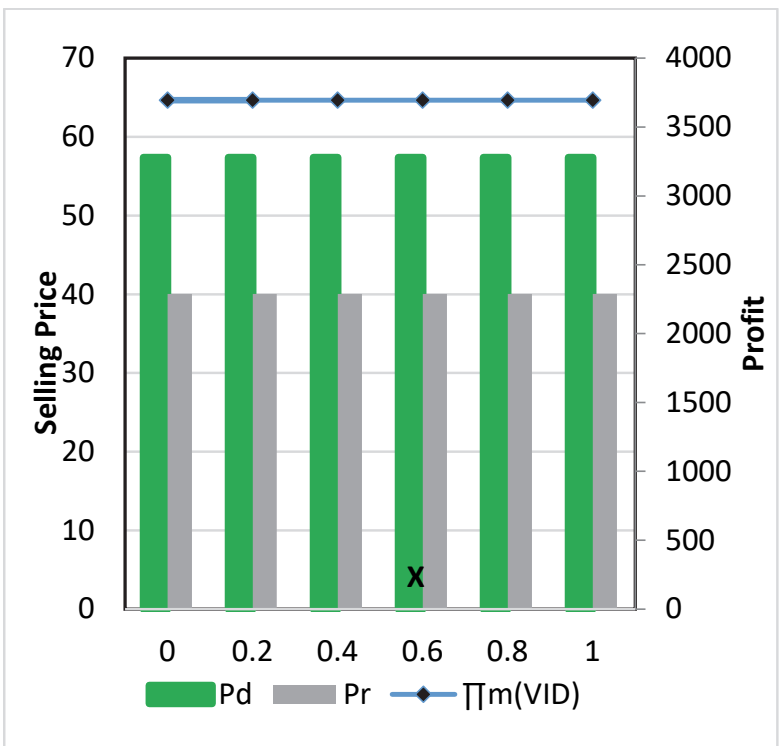

Fig. 1. (a) $\pi_{r}(V I D-S C), P_{r}$, and $P_{d} \mathrm{v} / \mathrm{s} X$

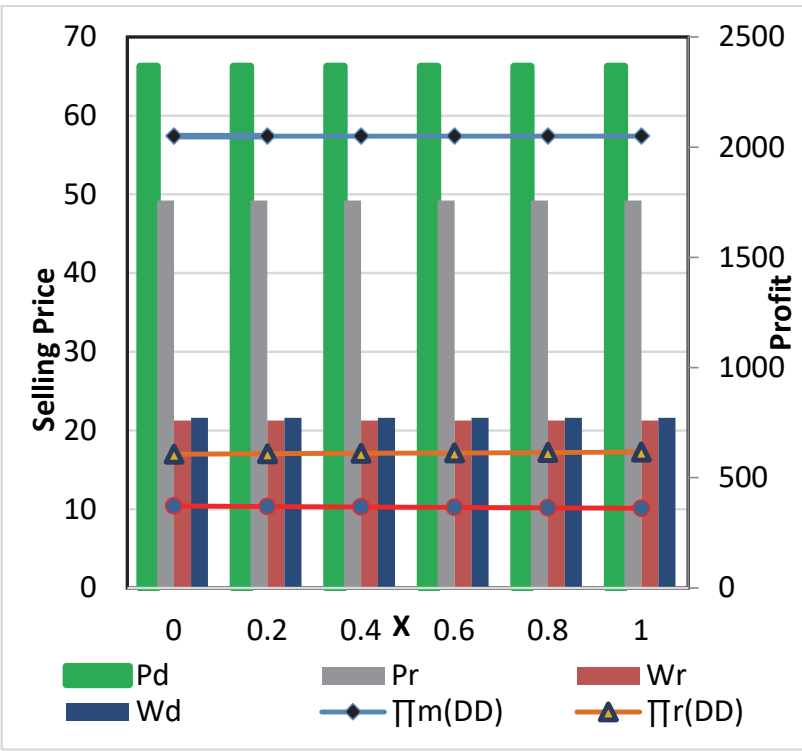

Fig. 1. (b) $\pi_{m}(D D-S C), \pi_{r}(D D-S C), \pi_{d(D D-S C)}, P_{r}, P_{d}, W_{r}$ and $W_{d} \mathrm{v} / \mathrm{s} X$ 


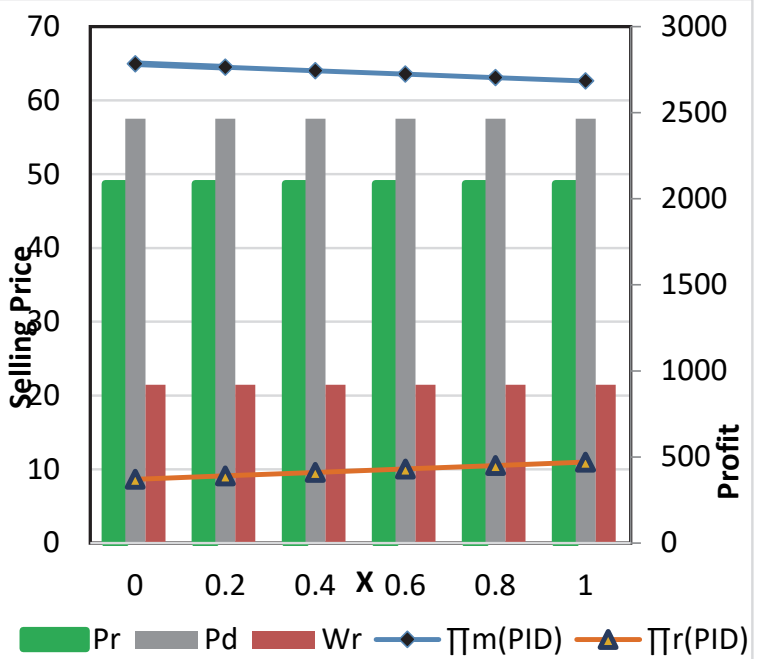

Fig. 1. (c) $\pi_{r(P I D-S C)} \pi_{m}(P I D-S C), P_{r}, P_{d}$ and $W_{r} \mathrm{v} / \mathrm{s} X$

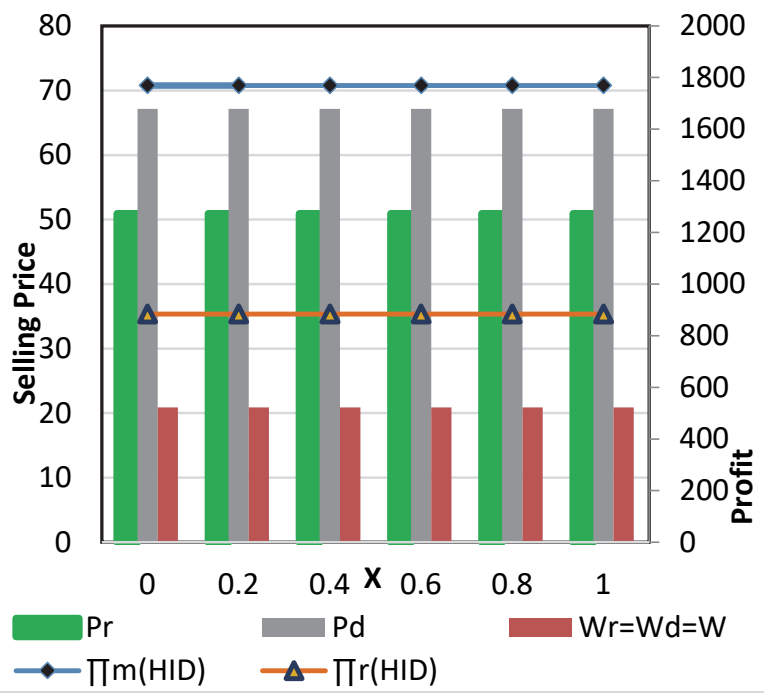

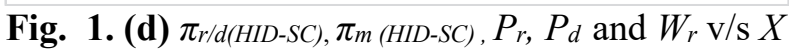

In VID-SC and HID-SC, retail and e-tail store works as a unit. Therefore, an advertisement cost sharing contract is not applicable and as a result channel's participation rate (X) for cooperative advertisement is absent in VID-SC and HID-SC. While in DD-SC and PID-SC configurations, retail and e-tail stores work as an individual to maximize individual's sales and profit. The effect of change in advertisement cost sharing factor for DD-SC and PID-SC is explained in corollary 1.

Corollary 1(a) For all channel configurations, with the change in cooperative advertisement, wholesale price $\left(W_{r}\right.$ and $\left.W_{d}\right)$ and optimum selling price $\left(P_{r}\right.$ and $\left.P_{d}\right)$ remain unchanged (For all channel configurations $\frac{d P_{r}{ }^{*}}{d X}=0, \frac{d P_{d}{ }^{*}}{d X}=0, \frac{d W_{r}}{d X}=0, \frac{d W_{d}}{d X}=0$ and $\left.\frac{d W_{r / d}}{d X}=0\right)$.

Corollary 1(a) articulates, the consumer get attracted with "how efficient the advertisement effort is done", but their purchase pattern is independent of "who is spending more for the advertisement". So the participation rate of advertisement is not affected by the selling piece.

Corollary 1(b) As $X$ approaches to 1, profit of e-channel become monotonic deceasing function of $X$ while profit of retail channel become monotonic increasing function of $X$, (For DD-SC and PID$S C \frac{d \pi_{r(D D-S C)}}{d X}>0, \frac{d \pi_{d(P I D-S C)}}{d X}<0, \frac{d \pi_{m(D D)}}{d X}=0, \frac{d \pi_{r(D D-S C)}}{d X}>0$ and $\left.\frac{d \pi_{d(P I D-S C)}}{d X}<0\right)$.

To take cost and demand benefit e-taier's starts contributing towards cooperative advertisement and his participation rate for advertisement increases with rise in customer's compatibility with e-channel. However, with the higher participation rate e-tailer loses certain profit share but the retailer's profit will continue to increase. The manufacturer who is not involved in the end selling (in DD-SC) stays unaffected with advertisement cost sharing factor by maintaining a constant profit value. For $X=0$ retailer bares all the advertising expenditures and holds minimum profit, at this stage e-tailer doesn't pay for advertisement and enjoys with the highest profit. As the value of $X$ starts moving towards 1, e-tailer starts contributing towards advertisement expenditure and as a result, e-tailer's profit starts declining. But the decline in profit due to cooperative advertisement is quite less compared to decline in profit without cooperation (Bergen and John, 1997; Yan et al., 2009; Zhou et al., 2018b). Without the cooperation e-tailers have to bare full advertisement expenditure $A$, and this makes product more costly as explain in observation 2. As a result, for the e-tailers profit value with and without cooperation is given as $\pi_{d_{\text {(with cooperation) }}>} \pi_{d_{\text {(without cooperation) }} \text {. At this stage, a well-defined cooperative advisement policy }}$ reduces the cost, effort and handling management in DD-SC and PID-SC. Thus, it is advisable for both the channel members to hold a cooperative advertisement policy, to reduce the burden on one channel and creates a win-win situation. A well-planned cooperative advertising strategy gives a successful marketing initiative for both the channel members to stimulate the demand and profit. 


\subsection{Effect of varying free-riding rate $(\tau)$}

Observation 4: $\frac{\partial D_{d}{ }^{*}}{\partial S}>0$ and $\frac{\partial D_{r}{ }^{*}}{\partial S}>0$, for $\tau>0.5 \frac{\partial D_{r}{ }^{*}}{\partial S}>\frac{\partial D_{d}{ }^{*}}{\partial S}$ and for $\tau \leq 0.5 \frac{\partial D_{r}{ }^{*}}{\partial S}<\frac{\partial D_{d}{ }^{*}}{\partial S}$.

Observation 4 says, with increase in sales effort demand at retail channel and e-channel increases. But when consumption/purchase pattern is more inclined to free-riding $(\tau>0.5)$ the rise in demand at retail channel is higher compared to the e-channel, and vice as versa. It means the demand swapping occur based on level of free-riding. One should consider product category and its associated value of freeriding to define sales effort and demand pattern (Pu et al., 2017).

Observation 5: For all channel configurations $\frac{\partial P_{r}{ }^{*}}{\partial S}>0$ and $\frac{\partial P_{d}{ }^{*}}{\partial S}>0$, but for $\tau>0.5 \frac{d P_{r}{ }^{*}}{d S}>\frac{d P_{d}{ }^{*}}{d S}$ and for $\tau \leq 0.5 \frac{d P_{r}{ }^{*}}{d S}<\frac{d P_{d}{ }^{*}}{d S}$.

Observation 5 implies a general observation as the channel member raise their sales efforts, their offered selling price also increases. But, for each channel structure, there exist an optimum value of $S^{*}$ (obtained by $\frac{\partial \pi^{*}}{\partial s}=0$ ) for price optimization and profit maximization. When consumers are more inclined towards free-riding $(\tau>0.5)$, the rate of change of retail selling price with respect to sales effort is much more than that of e-channel, and vice a versa happens when customers are not much inclined to freeriding $(\tau<0.5)$. For the various values of free-riding ratio, an effect on demand, price and profit is presented in Fig. 2 (a), (b), (c) and (d).

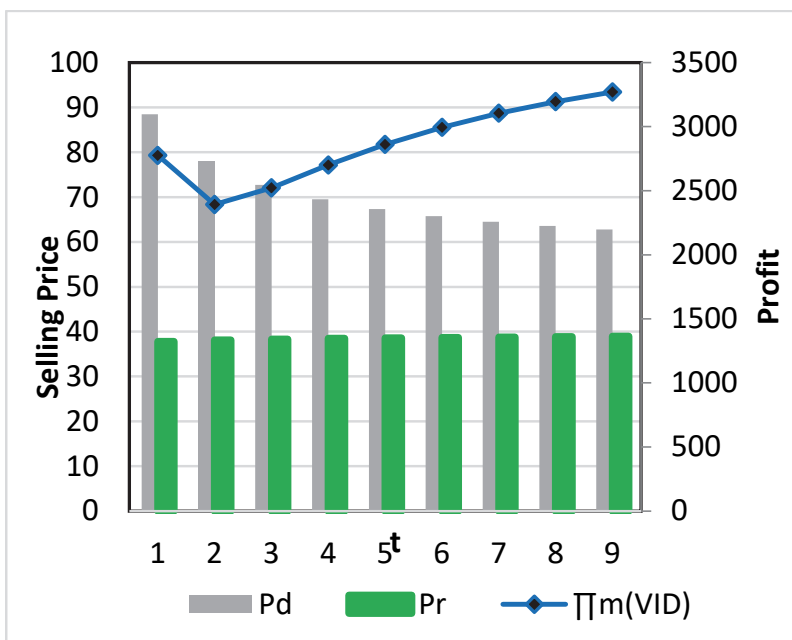

Fig. 3. (a) $\pi_{m}$ (VID-SC) $\mathrm{v} / \mathrm{s} t$

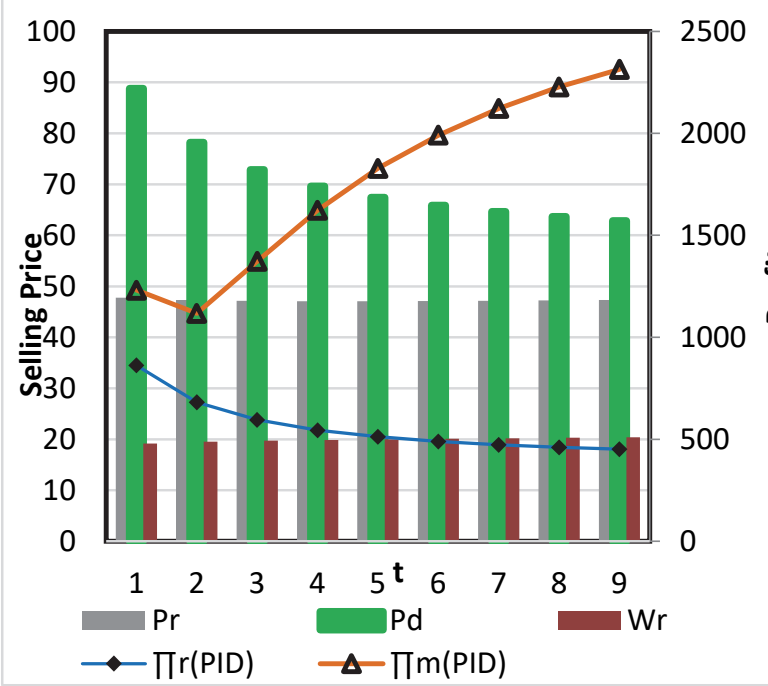

Fig. 3. (c) $\pi_{r(P I D-S C)} \pi_{m}(P I D-S C), P_{r}, P_{d}$ and $W_{r} \mathrm{v} / \mathrm{s} t$

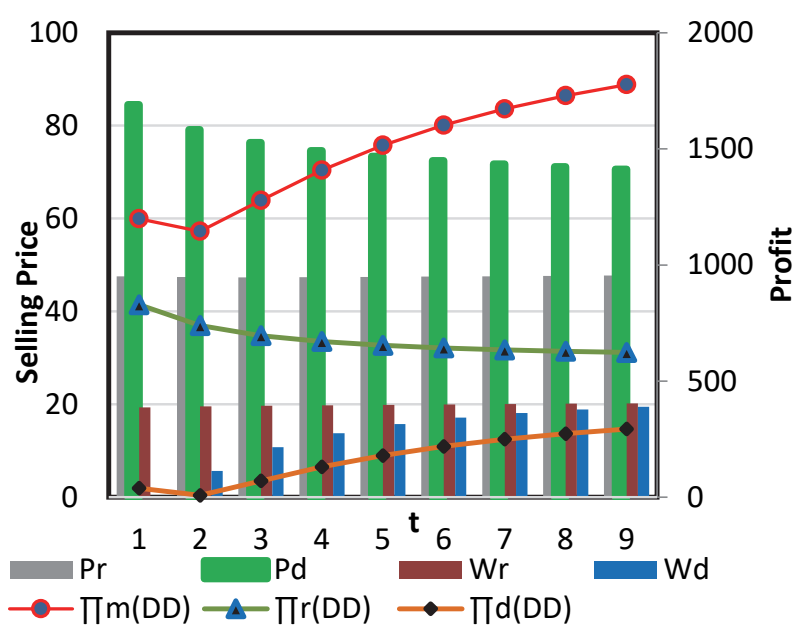

Fig. 3. (b) $\pi_{m(D D-S C)}, \pi_{r(D D-S C)}, \pi_{d(D D-S C)}, P_{r}, P_{d}, W_{r}$ and $W_{d} \mathrm{v} / \mathrm{s} t$

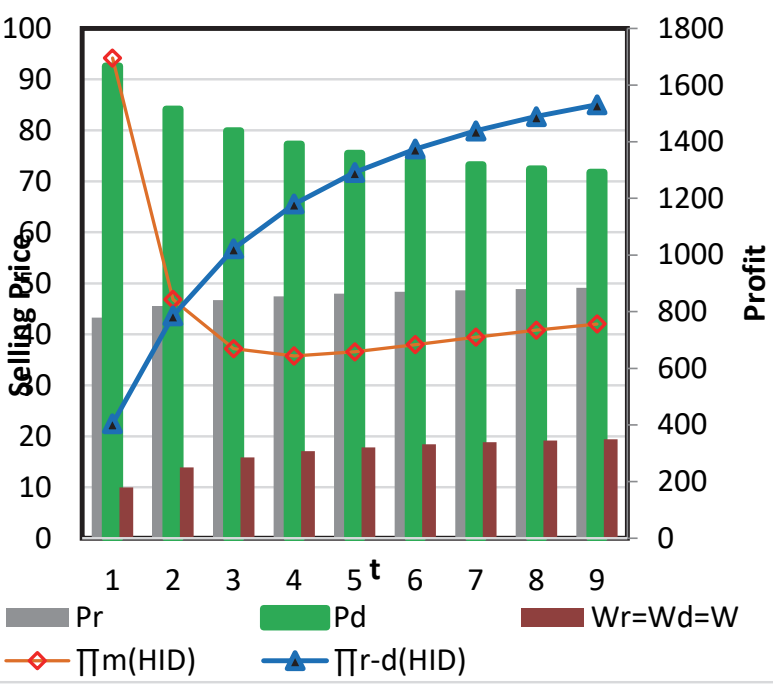

Fig. 3. (d) $\pi_{r(H I D-S C)} \pi_{m}(H I D-S C), P_{r}, P_{d}$ and $W_{r} \mathrm{v} / \mathrm{s} t$ 
Corollary 3(a-i) For PID-SC and HID-SC, the optimum wholesale price is monotonic increasing function of delivery lead time (For PID-SC and HID-SC for all values of ' $t$ ' $\frac{\partial W_{i}^{*}}{\partial t}>0$ ).

Corollary 3(a-ii) For DD-SC, retailer's optimum wholesale price $\left(W_{r}{ }^{*}\right)$ is always monotonic increasing function of delivery lead time ( $t)$, while e-tailer's optimum wholesale price $\left(W_{d}{ }^{*}\right)$ is decreasing function of delivery lead time up to a threshold value of time $\left(t^{*}\right)$ and after this point $W_{d}{ }^{*}$ becomes an increasing function of lead time, (For DD -SC, if $t<t^{*}$ then $\frac{\partial W_{r}{ }^{*}}{\partial t}>0, \frac{\partial W_{d}{ }^{*}}{\partial t}<0$ and if $t \geq t^{*}$ then $\frac{\partial W_{r}{ }^{*}}{\partial t}>$ $0, \frac{\partial W_{d}{ }^{*}}{\partial t}>0$ ). A manufacturer changes the wholesale price in response to demand conditions. Once goods are transferred to the retailer, he may not be able to change the wholesale price and the manufacturer may end up with unsold units. Thus to take cost benefit manufacturer starts offering products at higher wholesale price to the retailers. But in the case of DD-SC wholesale price decreases for the lead time below the threshold value and it starts increasing when $t$ reaches above the threshold value.

Corollary 3(b-i). When retail and e-channel work as a unit, their respective optimal selling prices are monotonic increasing and decreasing function of time respectively (For VID-SC and HID-SC for all values of $t \frac{\partial P_{r}{ }^{*}}{\partial t}>0$ and $\left.\frac{\partial P_{d}{ }^{*}}{\partial t}<0\right)$.

Corollary 3(b-ii) When both channel works as an individual, the optimal e-selling price is always decreasing function of time, while the relation of time with retail selling price initially drops and it starts increasing after a threshold value of time, (For DD -SC and PID -SC: If $t<t^{*}$ then $\frac{\partial P_{r}{ }^{*}}{\partial t}<$ 0 and $\frac{\partial P_{d}{ }^{*}}{\partial t}<0$ and if $t \geq t^{*}$ then $\frac{\partial P_{r}{ }^{*}}{\partial t}>0$ and $\left.\frac{\partial P_{d}{ }^{*}}{\partial t}<0\right)$.

Corollary 3(b-i and ii) describes a general fundamental, an e-tailer can offer product at lesser price when customers become less sensitive to delivery lead time, and this relation is versatile for all the channel configurations and for all the values of lead time. A threshold value of delivery lead time reflects a time period up to a customer can wait for the product. Beyond this limit $\left(t \geq t^{*}\right)$ however the price at e-tail store is low customer will swipe his demand to retail store and to take cost benefit retailer increases his selling price. But when e-tailer is capable of delivering product quickly $\left(t<t^{*}\right)$, retailer drop down his selling price to attract customers to stop switching them to e-tail store. A little consideration shows that the effect of $t$ on $P_{d}{ }^{*}$ and $P_{r}{ }^{*}$ depends on the channel configuration but always $\frac{\partial P_{r}{ }^{*}}{\partial t}-\frac{\partial P_{d}{ }^{*}}{\partial t}>0$. This reflects for the same change in $t$, change in retailer's selling price is greater than the e-channel's price change, because retailer's selling price is much more sensitive to lead time compared to e-channel's selling price. Thus, pricing policy of retail store is much more affected by delivery lead time then e-tail store (Hua et al., 2010).

Corollary 3(c-i): For all channel configurations, manufacturer's profit is monotonic increasing function of delivery lead time (For all channel configurations $\frac{d \pi_{m}{ }^{*}}{d t}>0$ ).

Corollary 3(c-ii) For all channel configurations, when lead time is below the threshold value retailer's profit is decreasing function of time, but after this point profit becomes an increasing function of time. (For all channel configurations when $t<t^{*}, \frac{d \pi_{r}{ }^{*}}{d t}<0$ and when $t \geq t^{*}, \frac{d \pi_{r}{ }^{*}}{d t}>0$ ).

Corollary 3(c-iii) For VID-SC, PID-SC and HID-SC, e-tailer's profit is monotonic increasing function of delivery lead time (For VID - SC, PID - SC and HID - SC under all values of $t \frac{d \pi_{d}^{*}}{d t}>0$ ). 
Corollary 3(c-iv) In DD-SC for a lead time less than the threshold value ( $\left.t^{*}\right)$ e-tailer's profit is monotonic decreasing function for delivery lead time, but after $t^{*}$ profit becomes an increasing function of delivery lead time (For $D D-S C$, if $t<t^{*} \frac{d \pi_{d(D D)^{*}}}{d t}<0$ and if $\left.t \geq t^{*} \frac{d \pi_{d(D D)^{*}}}{d t}>0\right)$.

The manufacturer is more profitable if lead time is longer (Corollary 3(c-i)). This relation holds good for all manufacturer- led dual-channel configurations (VID-SC, DD-SC, HID-SC and PID-SC). Thus, irrespective of channel configuration manufacturer is always gainful for longer lead time values. For the delivery time $t\left(t<t^{*}\right)$, customers are willing to wait for a product and this declines demand at retail store (Observation 5). Further, an increased offered wholesale price by manufacturer (Corollary 3-a) and decline in optimum selling price offered by retail (Corollary 3-b) weakens retailer's profit. But when delivery time $t\left(t \geq t^{*}\right)$, customers are not ready to wait too long for the product, creates a rise in demand at retail store (Observation 5) and rises in optimum selling price at retail store (Corollary 3-b), though the wholesale price offered by manufacturer is higher (Corollary 3-a), retailer can improvise this profit.

When e-channel is handled by an individual (like DD-SC) for shorter lead time (below the threshold value) profit of e-tailer reduces though demand is high (Observation 5), because certain portion of profit is used to provide quick delivery. Another observation says that if delivery lead time is higher than the threshold value, e-tailer can provide product at comparatively lesser price (Corollary 3-b) without compromising the profit. While for VID-SC, PID-SC and HID-SC the profit of e-channel and manufacturer always increases with the rise in delivery lead time, followed by corollary 3-c (i,ii and iii).

\subsection{Interaction among $X, \tau$ and $t$}

To analyses effect of a single variable on optimum selling price the results explained in above section is adequate. But, an interaction plot to represent the effect of more than one parameter is required. Here, Fig. 4, Fig. 5, Fig. 6 and Fig. 7 interaction plot for VID-SC, DD-SC, PID-SC and HID-SC channels are shown respectively.

Fig. 4(a and b), 5(a and b), 6(a and b) and 7( $\mathrm{a}$ and $\mathrm{b}$ ) shows the change in $\mathrm{P}_{\mathrm{r}}{ }^{*}$ and $\mathrm{P}_{\mathrm{d}}{ }^{*}$ with the change in $X$ and $\tau$ under a constant $t$. The plot represents $\mathrm{P}_{\mathrm{r}}{ }^{*}$ is in decreasing function while $\mathrm{P}_{\mathrm{d}}{ }^{*}$ is an increasing function of $\tau$, and an independent function of $X$. The product range having higher rate of free-riding ratio will be less costly at retail store and expensive at e-tail store. This relation supports results of Corollary 1 and 2 as well.

In Fig. 4(c and d), 5(c and d), 6(c and d) and 7(c and d) presents the change in $\mathrm{P}_{\mathrm{r}}{ }^{*}$ and $\mathrm{P}_{\mathrm{d}}{ }^{*}$ with the change in $t$ and $\tau$ under a constant $X$. The plot illustrates, $\mathrm{P}_{\mathrm{r}}{ }^{*}$ is a decreasing function of $\tau$ and an increasing function of $t$. Product is least costly at retail channel when it is delivered at a longer lead time with a greater value of free-riding ratio and vice a versa results are obtained for e-channel as it is an increasing function of $\tau$ and a decreasing function of $t$.

Here, 4(e and f), 5(e and f), 6(e and f) and 7(e and f) presents the change in $\mathrm{P}_{\mathrm{r}}{ }^{*}$ and $\mathrm{P}_{\mathrm{d}}{ }^{*}$ with the change in $X$ and $t$ values when $\tau$ is constant. The interaction plot is a linear and only a function of $\mathrm{t}$, and $X$ is an independent function (Corollary 1). Here, $\mathrm{P}_{\mathrm{r}}{ }^{*}$ is an increasing and $\mathrm{P}_{\mathrm{d}}{ }^{*}$ is a decreasing function of $\mathrm{t}$. Therefore, in order to keep the lower optimum selling price the retailer should focus on minimizing while the e-tailer need a greater delivery lead time. 

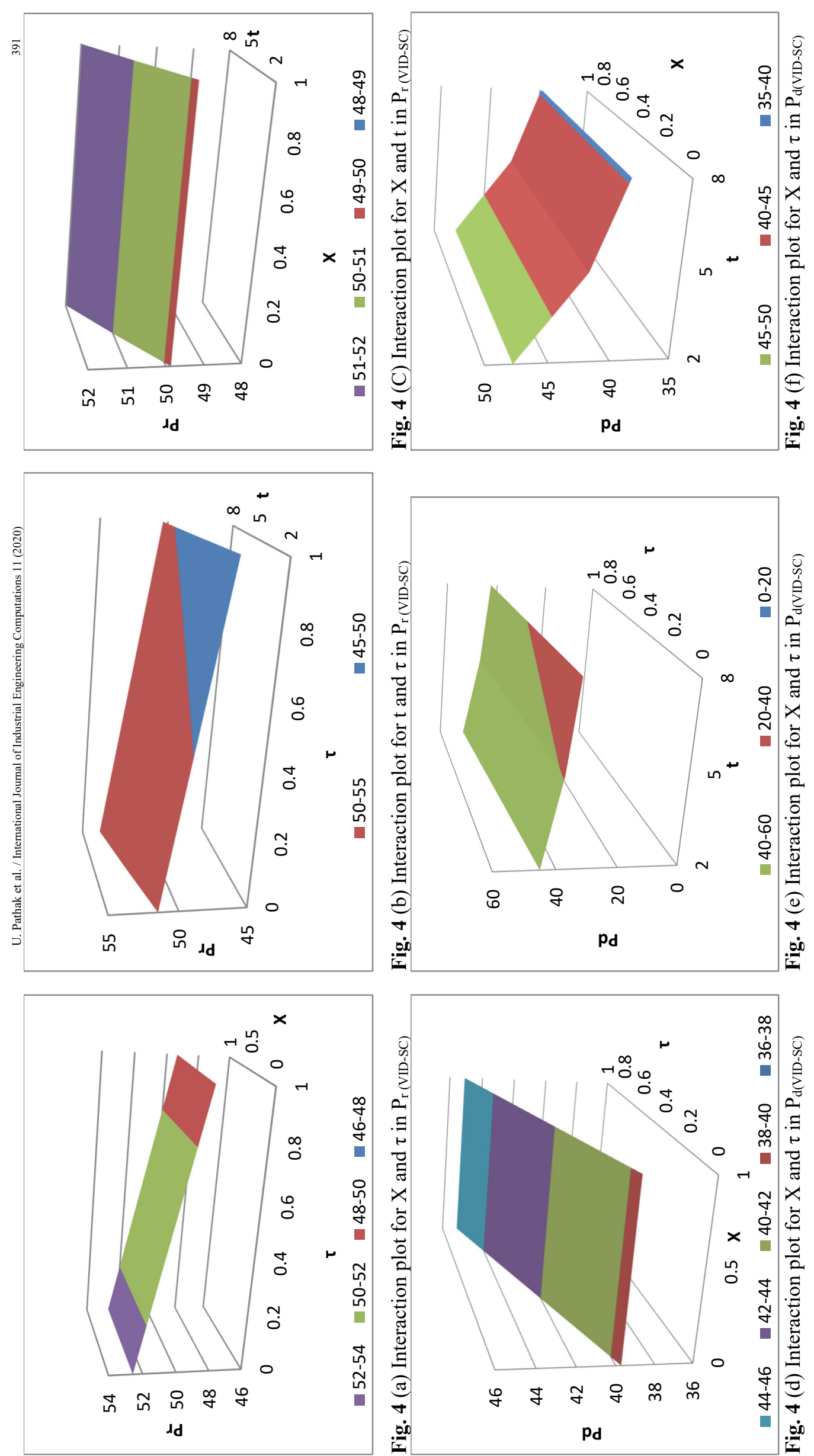

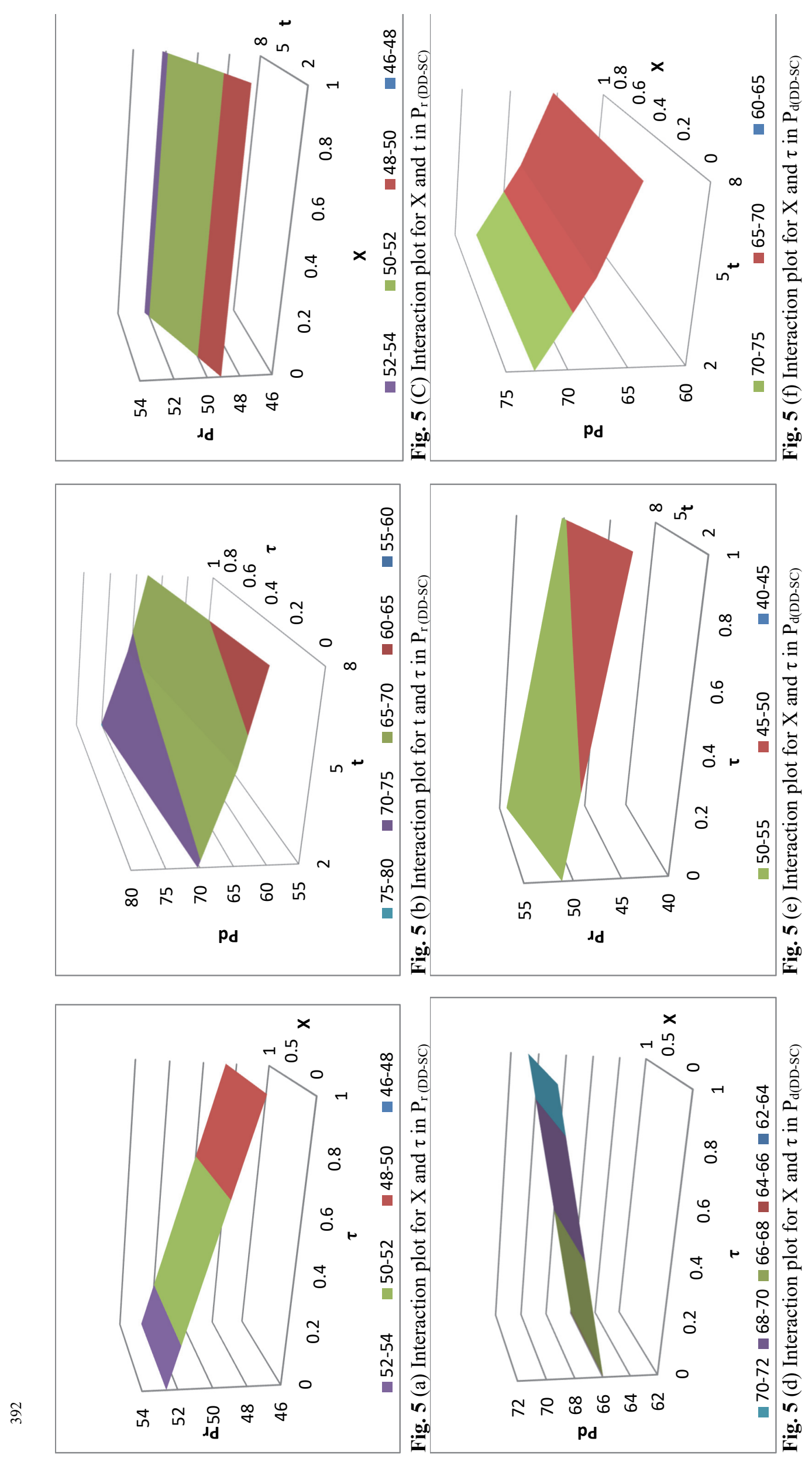

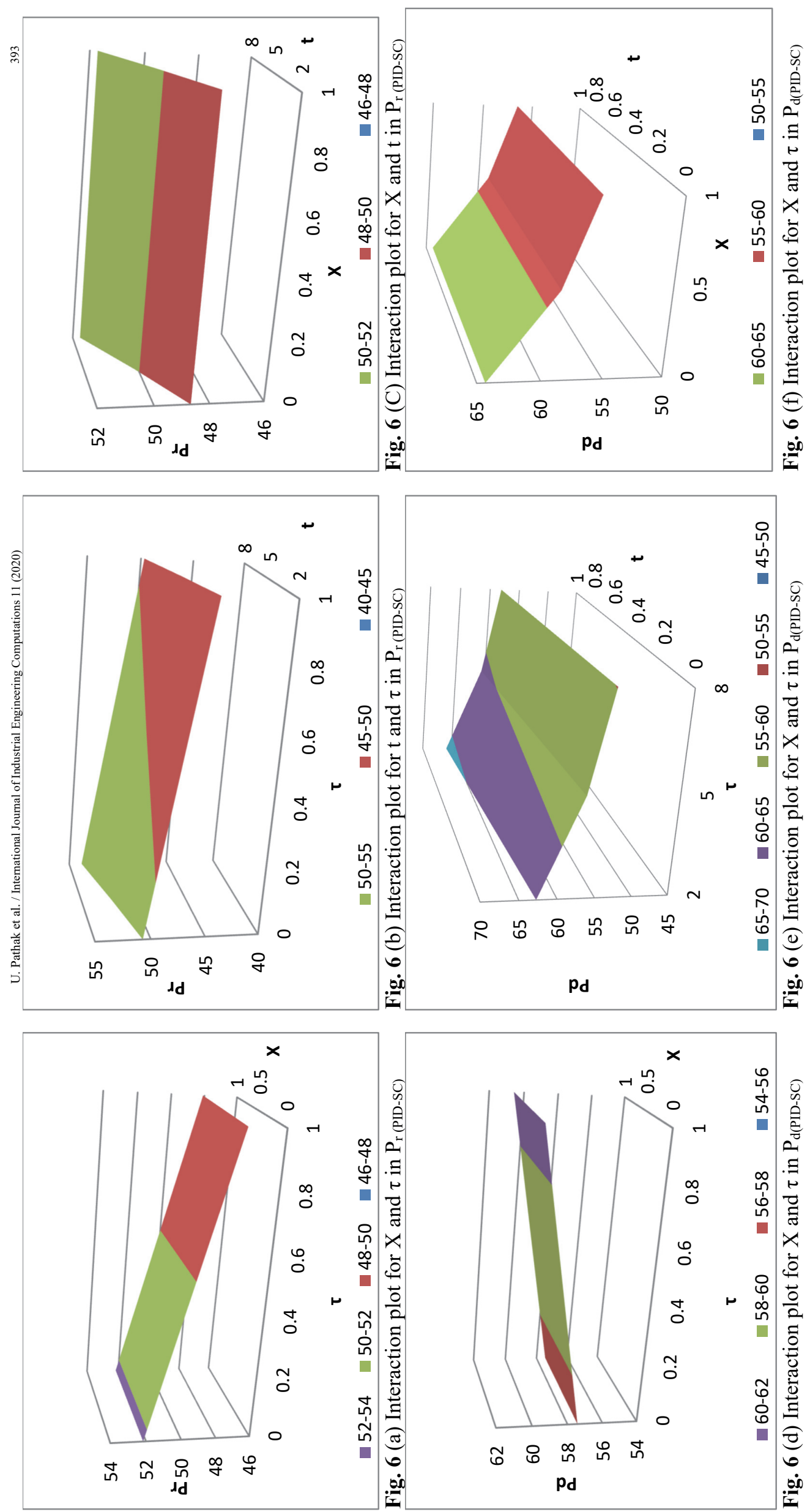

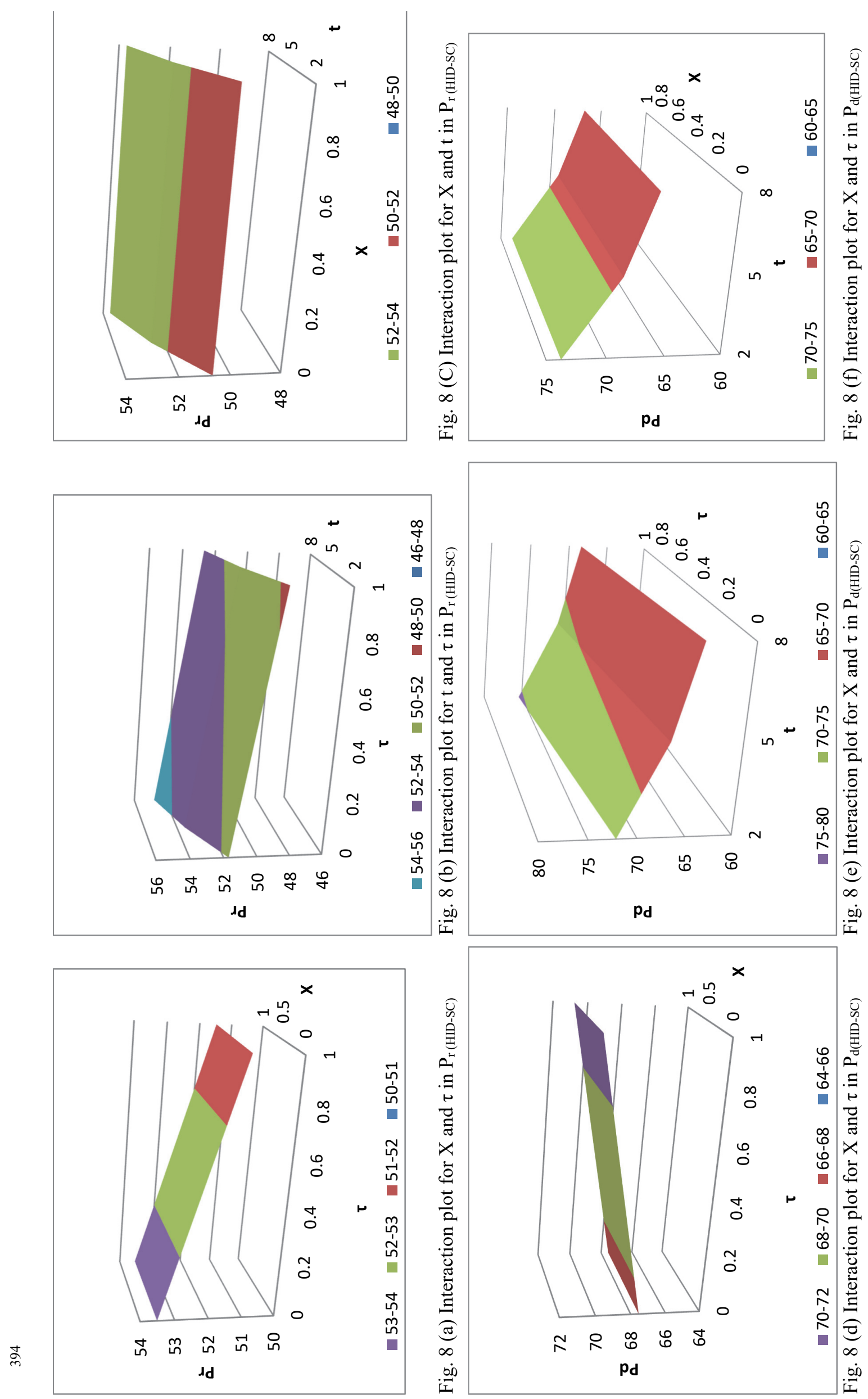


\section{Conclusion}

This paper has developed a dual-channel supply chain model consisting of four different manufacturerled configurations (VID-SC, DD-SC, PID-SC and HID-SC) and three different demand affecting parameters (cooperative advertisement, lead time and free-riding). A numerical example is carried out to obtain the results and it is briefly explained in section 4 . Table 3 explains general outline of all the observations and results obtain from this study, this helps for the channel configuration selection and for the choosing best fit values of decision parameters. A decision maker can easily predict the values of outcome by changing values of the decision parameters to make future strategies without actual implementation. The relation explained in Table 3 is valid for all possible values of decision parameters.

Table 3

Comparative Summary

\begin{tabular}{|c|c|c|c|c|}
\hline Channel & $\begin{array}{l}\text { Decision } \\
\text { Variable }\end{array}$ & $\begin{array}{l}\text { Effect of varying } \\
\text { channels participation } \\
\text { rate on total } \\
\text { advertisement }(X) \\
\text { from } 0 \text { to } 1\end{array}$ & $\begin{array}{l}\text { Effect of varying free } \\
\text { riding rate }(\tau) \text { from } 0 \\
\text { to } 1\end{array}$ & $\begin{array}{l}\text { Effect of varying delivery lead time } \\
(t) \text { from } 2 \text { to } 10\end{array}$ \\
\hline \multirow{3}{*}{ VID-SC } & $\prod_{m(V I D)}$ & Remains same & Increases & Decreases then increases \\
\hline & $P_{r}^{*}$ & Remains same & Decreases & Increases \\
\hline & $P_{d}{ }^{*}$ & Remains same & Increases & Decreases \\
\hline \multirow{7}{*}{ DD-SC } & $\prod_{m(D D)}$ & Remains same & Increases & Decreases then increases \\
\hline & $\prod_{r(D D)}$ & Increases & Increases & Decreases \\
\hline & $\prod_{d(D D)}$ & Decreases & Increases & Decreases then increases \\
\hline & $P_{r}^{*}$ & Remains same & Decreases & Decreases then increases \\
\hline & $P_{d}{ }^{*}$ & Remains same & Increases & Decreases \\
\hline & $W_{r}^{*}$ & Remains same & Decreases & Increases \\
\hline & $W_{d}^{*}$ & Remains same & Increases & Decreases \\
\hline \multirow{5}{*}{ PID-SC } & $\prod_{m(P I D)}$ & Decreases & Increases & Decreases then increases \\
\hline & $\prod d(P I D)$ & Increases & Increases & Decreases \\
\hline & $P_{r}^{*}$ & Remains same & Decreases & Decreases then increases \\
\hline & $P_{d}^{*}$ & Remains same & Increases & Decreases \\
\hline & $W_{r}^{*}$ & Remains same & Decreases & Increases \\
\hline \multirow{5}{*}{ HID-SC } & $\prod m(H I D)$ & Remains same & Decreases & Decreases then increases \\
\hline & $\prod r_{-} d(H I D)$ & Remains same & Increases & Increases \\
\hline & $P_{r}^{*}$ & Remains same & Decreases & Increases \\
\hline & $P_{d}{ }^{*}$ & Remains same & Increases & Decreases \\
\hline & $W$ & Remains same & Decreases & Increases \\
\hline
\end{tabular}

The model development and analysis have some limitations. These limitations can be overcome with the suggested future scope as follows: It would be an interesting mode of study for demand function with a stochastic behaviour under asymmetric information. In this study noise factors are not considered. Apart of advertisement, lead time and free-riding, certain uncertainties like bull-whip effect, environmental factors, government tax and policy, consumer's behaviour etc. also influence the demand, price and profit to make it more robust. The developed model is calculated by considering manufacturer's and channel member's approach of profit maximization. It will be an interesting to examine the impact of customer's desire and comfort in procurement, to re-calculate the model from customer's point of view. It will be interesting to apply some other well established coordination contracts as revenue sharing, profit sharing, stock sharing and customer sharing mechanisms. 


\section{References}

Batarfi, R., Jaber, M. Y., \& Aljazzar, S. M. (2017). A profit maximization for a reverse logistics dualchannel supply chain with a return policy. Computers \& Industrial Engineering, 106, 58-82.

Batarfi, R., Jaber, M. Y., \& Zanoni, S. (2016). Dual-channel supply chain: A strategy to maximize profit. Applied Mathematical Modelling, 40(21-22), 9454-9473.

Bergen, M., \& John, G. (1997). Understanding cooperative advertising participation rates in conventional channels. Journal of Marketing Research, 34(3), 357-369.

Brandon-Jones, A., \& Kauppi, K. (2018). Examining the antecedents of the technology acceptance model within e-procurement. International Journal of Operations \& Production Management, 38(1), 22-42.

Cai, G. G., Zhang, Z. G., \& Zhang, M. (2009). Game theoretical perspectives on dual-channel supply chain competition with price discounts and pricing schemes. International Journal of Production Economics, 117(1), 80-96.

Chen, K. Y., Kaya, M., \& Özer, Ö. (2008). Dual sales channel management with service competition. Manufacturing \& Service Operations Management, 10(4), 654-675.

Chen, J., Liang, L., Yao, D. Q., \& Sun, S. (2017). Price and quality decisions in dual-channel supply chains. European Journal of Operational Research, 259(3), 935-948.

Chen, T. H. (2015). Effects of the pricing and cooperative advertising policies in a two-echelon dualchannel supply chain. Computers \& Industrial Engineering, 87, 250-259.

Chiang, W. Y. K., Chhajed, D., \& Hess, J. D. (2003). Direct marketing, indirect profits: A strategic analysis of dual-channel supply-chain design. Management science, 49(1), 1-20.

Choi, S. C. (2003). Expanding to direct channel: Market coverages as entry barrier. Journal of Interactive Marketing, 17(1), 25-40.

Chung, W., Talluri, S., \& Kovács, G. (2018). Investigating the effects of lead-time uncertainties and safety stocks on logistical performance in a border-crossing JIT supply chain. Computers \& Industrial Engineering, 118, 440-450.

Chutani, A., \& Sethi, S. P. (2018). Dynamic cooperative advertising under manufacturer and retailer level competition. European Journal of Operational Research, 268(2), 635-652.

Clegg, B., Wang, T., \& Ji, P. (2010). Understanding customer needs through quantitative analysis of Kano's model. International Journal of Quality \& Reliability Management, 173-184.

Dan, B., Liu, C., Xu, G., \& Zhang, X. (2014). Pareto improvement strategy for service-based free-riding in a dual-channel supply chain. Asia-Pacific Journal of Operational Research, 31(06), 1450050.

Dan, B., Xu, G., \& Liu, C. (2012). Pricing policies in a dual-channel supply chain with retail services. International Journal of Production Economics, 139(1), 312-320.

Esmaeili, M., Naghavi, M. S., \& Ghahghaei, A. (2018). Optimal (R, Q) policy and pricing for twoechelon supply chain with lead time and retailer's service-level incomplete information. Journal of Industrial Engineering International, 14(1), 43-53.

Feng, L., Govindan, K., \& Li, C. (2017). Strategic planning: Design and coordination for dual-recycling channel reverse supply chain considering consumer behavior. European Journal of Operational Research, 260(2), 601-612.

Galih, S. (2012). Cloud computing scheme for lower IT cost in Indonesian government's e-procurement system. International Journal of Information and Communication Technology, 4(2-4), 187-197.

Gao, J., Wang, X., Yang, Q., \& Zhong, Q. (2016). Pricing decisions of a dual-channel closed-loop supply chain under uncertain demand of indirect channel. Mathematical Problems in Engineering, 2016.

Giri, B. C., \& Bardhan, S. (2014). Note on "Coordinating the ordering and advertising policies for a single-period commodity in a two-level supply chain”. Computers \& Industrial Engineering, 77, 1114.

Giri, B. C., Chakraborty, A., \& Maiti, T. (2017). Pricing and return product collection decisions in a closed-loop supply chain with dual-channel in both forward and reverse logistics. Journal of manufacturing systems, 42, 104-123.

Guo, Z., \& Ma, J. (2018). Dynamics and implications on a cooperative advertising model in the supply 
chain. Communications in Nonlinear Science and Numerical Simulation, 64, 198-212.

He, R., Xiong, Y., \& Lin, Z. (2016). Carbon emissions in a dual-channel closed loop supply chain: the impact of consumer free-riding behavior. Journal of Cleaner Production, 134, 384-394.

Hua, G., Wang, S., \& Cheng, T. E. (2010). Price and lead time decisions in dual-channel supply chains. European journal of operational research, 205(1), 113-126.

Huang, S., Chen, G., \& Ma, Y. (2015). Online channel operation mode: Game theoretical analysis from the supply chain power structure. Journal of Industrial Engineering and Management (JIEM), 8(5), 1602-1622.

Huang, S., Yang, C., \& Zhang, X. (2012). Pricing and production decisions in dual-channel supply chains with demand disruptions. Computers \& Industrial Engineering, 62(1), 70-83.

JI, K. (2016). Research on Cooperative Advertising Decisions in Dual-Channel Supply Chain Under Asymmetric Demand Information When Online Channel Implements Discount Promotion. Management Science and Engineering, 10(4), 13-19.

Karray, S., Martín-Herrán, G., \& Sigué, S. P. (2017). Cooperative advertising for competing manufacturers: The impact of long-term promotional effects. International Journal of Production Economics, 184, 21-32.

Khouja, M., \& Wang, Y. (2010). The impact of digital channel distribution on the experience goods industry. European Journal of Operational Research, 207(1), 481-491.

Kundu, S., \& Chakrabarti, T. (2018). Joint Optimal Decisions on Pricing and Local Advertising Policy of a Socially Responsible Dual-Channel Supply Chain. American Journal of Mathematical and Management Sciences, 37(2), 117-143.

Kundu, S., \& Chakrabarti, T. (2018). Joint Optimal Decisions on Pricing and Local Advertising Policy of a Socially Responsible Dual-Channel Supply Chain. American Journal of Mathematical and Management Sciences, 37(2), 117-143.

Li, F., \& Huang, B. (2012, July). The impact of product category on pricing decision in a two-echelon dual-channel supply chain. In Proceedings of 2012 IEEE International Conference on Service Operations and Logistics, and Informatics (pp. 269-272). IEEE.

Li, Y., Xu, F., \& Zhao, X. (2017). Governance mechanisms of dual-channel reverse supply chains with informal collection channel. Journal of cleaner production, 155, 125-140.

Mahar, S., Bretthauer, K. M., \& Venkataramanan, M. A. (2009). The value of virtual pooling in dual sales channel supply chains. European Journal of Operational Research, 192(2), 561-575.

Mahar, S., Salzarulo, P. A., \& Wright, P. D. (2012). Using online pickup site inclusion policies to manage demand in retail/E-tail organizations. Computers \& Operations Research, 39(5), 991-999.

Matsui, K. (2016). Asymmetric product distribution between symmetric manufacturers using dualchannel supply chains. European Journal of Operational Research, 248(2), 646-657.

Matsui, K. (2016). Asymmetric product distribution between symmetric manufacturers using dualchannel supply chains. European Journal of Operational Research, 248(2), 646-657.

Modak, N. M., \& Kelle, P. (2019). Managing a dual-channel supply chain under price and delivery-time dependent stochastic demand. European Journal of Operational Research, 272(1), 147-161.

Mukhopadhyay, S. K., \& Setoputro, R. (2004). Reverse logistics in e-business: Optimal price and return policy. International Journal of Physical Distribution \& Logistics Management, 34(1), 70-89.

Panda, S., Modak, N. M., Sana, S. S., \& Basu, M. (2015). Pricing and replenishment policies in dualchannel supply chain under continuous unit cost decrease. Applied Mathematics and Computation, 256, 913-929.

$\mathrm{Pu}, \mathrm{X}$., Gong, L., \& Han, X. (2017). Consumer free-riding: Coordinating sales effort in a dual-channel supply chain. Electronic Commerce Research and Applications, 22, 1-12.

Ren, L., He, Y., \& Song, H. (2014). Price and service competition of dual-channel supply chain with consumer returns. Discrete Dynamics in Nature and Society, 2014.

Ryan, J. K., Sun, D., \& Zhao, X. (2012). Coordinating a supply chain with a manufacturer-owned online channel: A dual-channel model under price competition. IEEE Transactions on Engineering Management, 60(2), 247-259.

Modak, N. M., \& Kelle, P. (2019). Managing a dual-channel supply chain under price and delivery-time 
dependent stochastic demand. European Journal of Operational Research, 272(1), 147-161.

Shi, K., \& Ma, H. (2016). Evolution Of Trust In A Dual-Channel Supply Chain Considering Reciprocal Altruistic Behavior. Advances in Complex Systems, 19(06n07), 1650014.

Soleimani, F. (2016). Optimal pricing decisions in a fuzzy dual-channel supply chain. Soft Computing, 20(2), 689-696.

Tsao, Y. C., \& Su, P. Y. (2012). A dual-channel supply chain model under price and warranty competition. International Journal of Innovative Computing, Information and Control, 8(3), 21252135.

Tsay, A. A., \& Agrawal, N. (2004). Channel conflict and coordination in the e-commerce age. Production and operations management, 13(1), 93-110.

Wang, L., Song, H., \& Wang, Y. (2017). Pricing and service decisions of complementary products in a dual-channel supply chain. Computers \& industrial engineering, 105, 223-233.

Xiao, T., \& Shi, J. J. (2016). Pricing and supply priority in a dual-channel supply chain. European Journal of Operational Research, 254(3), 813-823.

Xie, J., Liang, L., Liu, L., \& Ieromonachou, P. (2017). Coordination contracts of dual-channel with cooperation advertising in closed-loop supply chains. International Journal of Production Economics, 183, 528-538.

Xu, H., Liu, Z. Z., \& Zhang, S. H. (2012). A strategic analysis of dual-channel supply chain design with price and delivery lead time considerations. International Journal of Production Economics, 139(2), 654-663.

Yan, B., Jin, Z., Liu, Y., \& Yang, J. (2018). Decision on risk-averse dual-channel supply chain under demand disruption. Communications in Nonlinear Science and Numerical Simulation, 55, 206-224.

Yan, R., Ghose, S., \& Bhatnagar, A. (2006). Cooperative advertising in a dual-channel supply chain. International Journal of Electronic Marketing and Retailing, 1(2), 99-114.

Yan, R., \& Pei, Z. (2015). The strategic value of cooperative advertising in the dual-channel competition. International Journal of Electronic Commerce, 19(3), 118-143.

Yan, R., Pei, Z., \& Myers, C. (2016). Do channel members value the multiple-cooperation strategy?. Journal of Retailing and Consumer Services, 30, 84-95.

Yang, J. Q., Zhang, X. M., Fu, H. Y., \& Liu, C. (2017). Inventory competition in a dual-channel supply chain with delivery lead time consideration. Applied Mathematical Modelling, 42, 675-692.

Yoo, W. S., \& Lee, E. (2011). Internet channel entry: A strategic analysis of mixed channel structures. Marketing Science, 30(1), 29-41.

Yue, X., \& Liu, J. (2006). Demand forecast sharing in a dual-channel supply chain. European Journal of Operational Research, 174(1), 646-667.

Zhao, F., Wu, D., Liang, L., \& Dolgui, A. (2016). Lateral inventory transshipment problem in online-tooffline supply chain. International Journal of Production Research, 54(7), 1951-1963.

Zhou, Y. W., Li, J., \& Zhong, Y. (2018). Cooperative advertising and ordering policies in a two-echelon supply chain with risk-averse agents. Omega, 75, 97-117.

\section{Appendix}

\section{Appendix A :}

Taking second order partial derivatives of Eq. (1) with $P_{r} a n d P_{d}$ gives Hessian matrix $\mathrm{H}_{1}$ as:

$$
\begin{aligned}
& \mathrm{H}_{1}=\left[\begin{array}{cc}
\partial^{2} \pi_{m(V I D)} / \partial P_{r}{ }^{2} & \partial^{2} \pi_{m(V I D)} / \partial P_{r} P_{d} \\
\partial^{2} \pi_{m(V I D)} / \partial P_{d} P_{r} & \partial^{2} \pi_{m(V I D)} / \partial P_{d}{ }^{2}
\end{array}\right]=\left[\begin{array}{cc}
-2 \alpha_{1} & \beta_{1}+\beta_{2} \\
\beta_{1}+\beta_{2} & -2 \alpha_{1}
\end{array}\right] \\
& \partial^{2} \pi_{m(V I D)} / \partial P_{r}{ }^{2}=-2 \alpha_{1}<0 \text { and }\left|\begin{array}{cc}
-2 \alpha_{1} & \beta_{1}+\beta_{2} \\
\beta_{1}+\beta_{2} & -2 \alpha_{1}
\end{array}\right|=4 \alpha_{1} \alpha_{2}-2\left(\beta_{1}+\beta_{2}\right)>0 .
\end{aligned}
$$


A negatively definite Hessian matrix $\mathrm{H}_{1}$ shows $\pi_{m(V I D)}$ is strictly concave in $P_{r}$ and $P_{d}$.

\section{Appendix C}

Taking second order partial derivatives of Eq. (7) and Eq. (8) with $P_{r}$ and $P_{d}$ gives the Hessian matrix $\mathrm{H}_{2}$ as:

$\mathrm{H}_{2}=\left[\begin{array}{cc}\partial^{2} \pi_{r(D D)} / \partial P_{r}^{2} & \partial^{2} \pi_{r(D D)} / \partial P_{r} P_{d} \\ \partial^{2} \pi_{d(D D)} / \partial P_{d} P_{r} & \partial^{2} \pi_{d(D D)} / \partial P_{d}^{2}\end{array}\right]=\left[\begin{array}{cc}-2 \alpha_{1} & \beta_{1} \\ \beta_{2} & -2 \alpha_{1}\end{array}\right]$

$\partial^{2} \pi_{r(D D)} / \partial P_{r}^{2}=-2 \alpha_{1}<0$ and $H_{2}=\left|\begin{array}{cc}-2 \alpha_{1} & \beta_{1} \\ \beta_{2} & -2 \alpha_{1}\end{array}\right|=4 \alpha_{1} \alpha_{2}-\left(\beta_{1} \beta_{2}\right)>0$.

$\pi_{r(D D)}$ is strictly concave in $P_{r}$ and $P_{d}$.

Taking second order partial derivatives of eq.(6) with $W_{r}$ and $W_{d}$ obtained the Hessian matrix $\mathrm{H}_{3}$ as:

$\mathrm{H}_{3}=\left[\begin{array}{cc}\partial^{2} \pi_{m(D D)} / \partial W_{r}{ }^{2} & \partial^{2} \pi_{m(D D)} / \partial W_{r} W_{d} \\ \partial^{2} \pi_{m(D D)} / \partial W_{d} P_{r} & \partial^{2} \pi_{m(D D)} / \partial W_{d}{ }^{2}\end{array}\right]=\left[\begin{array}{cc}\frac{2 \alpha_{1} \beta_{1} \beta_{2}-4 \alpha_{1}{ }^{2} \alpha_{2}}{4 \alpha_{1} \alpha_{2}-\beta_{1} \beta_{2}} & \beta_{1} \\ \beta_{2} & \frac{2 \alpha_{1} \beta_{1} \beta_{2}-4 \alpha_{2}{ }^{2} \alpha_{1}}{4 \alpha_{1} \alpha_{2}-\beta_{1} \beta_{2}}\end{array}\right]$

Since, ${ }^{2} \pi_{m(D D)} / \partial W_{r}{ }^{2}=\frac{2 \alpha_{1} \beta_{1} \beta_{2}-4 \alpha_{1}^{2} \alpha_{2}}{4 \alpha_{1} \alpha_{2}-\beta_{1} \beta_{2}}<0$,

$\partial^{2} \pi_{m(D D)} / \partial W_{d}{ }^{2}=\frac{2 \alpha_{1} \beta_{1} \beta_{2}-4 \alpha_{2}^{2} \alpha_{1}}{4 \alpha_{1} \alpha_{2}-\beta_{1} \beta_{2}}<0$ and

$H_{3}=\left|\begin{array}{cc}\frac{2 \alpha_{1} \beta_{1} \beta_{2}-4 \alpha_{1}{ }^{2} \alpha_{2}}{4 \alpha_{1} \alpha_{2}-\beta_{1} \beta_{2}} & \beta_{1} \\ \beta_{2} & \frac{2 \alpha_{1} \beta_{1} \beta_{2}-4 \alpha_{2}{ }^{2} \alpha_{1}}{4 \alpha_{1} \alpha_{2}-\beta_{1} \beta_{2}}\end{array}\right|=\left(\left(\frac{2 \alpha_{1} \beta_{1} \beta_{2}-4 \alpha_{1}^{2} \alpha_{2}}{4 \alpha_{1} \alpha_{2}-\beta_{1} \beta_{2}} * \frac{2 \alpha_{1} \beta_{1} \beta_{2}-4 \alpha_{2}^{2} \alpha_{1}}{4 \alpha_{1} \alpha_{2}-\beta_{1} \beta_{2}}\right)-\left(\beta_{1} \beta_{2}\right)\right)>0$

$\pi_{m(D D)}$ is strictly concave in $W_{r}$ and $W_{d}$.

\section{Appendix D}

Taking second order partial derivatives of Eq. (13) and Eq. (14) with $P_{r}$ and $P_{d}$ gives the Hessian matrix $\mathrm{H}_{4}$ as:

$\mathrm{H}_{4}=\left[\begin{array}{cc}\partial^{2} \pi_{r(P I D)} / \partial P_{r}^{2} & \partial^{2} \pi_{r(P I D)} / \partial P_{r} P_{d} \\ \partial^{2} \pi_{m(P I D)} / \partial P_{d} P_{r} & \partial^{2} \pi_{m(P I D)} / \partial P_{d}{ }^{2}\end{array}\right]=\left[\begin{array}{cc}-2 \alpha_{1} & \beta_{1} \\ \beta_{2} & -2 \alpha_{2}\end{array}\right]$

$\pi_{r(P I D)}$ is strictly concave in $P_{r}$ and $P_{d}$. Consequently second derivative of $\pi_{m(P I D)}$ with respect to $W_{r}$ is given by:

$\partial^{2} \pi_{m(P I D)} / \partial W_{r}=\frac{\beta_{1} A 2}{A 1}-\frac{2 \alpha_{1}\left(t \beta_{1}{ }^{2}+2 \alpha_{1} \alpha_{2} t\right)}{A 1}+\frac{A 2\left(\frac{\beta_{2}\left(t \beta_{1}{ }^{2}+2 \alpha_{1} \alpha_{2} t\right)}{A 1}-\frac{\alpha_{2} A 2}{2 A 1}\right)}{A 1}<0$

$\mathrm{A} 1=t *\left(4 \alpha_{1} \alpha_{2}-\beta_{1} \beta_{2}\right)$ and A2 $=\mathrm{t}^{*}\left(4 \alpha_{1} \beta_{1}+2 \alpha_{1} \beta_{2}\right)$, shows $\pi_{m(P I D)}$ is strictly concave in $P_{r}, P_{d}$ and $W_{r}$ 


\section{Appendix E}

Taking second order partial derivatives of eq.(20) with $P_{r}$ and $P_{d}$ obtained the Hessian matrix $\mathrm{H}_{5}$ as:

$\mathrm{H}_{5}=\left[\begin{array}{cc}\partial^{2} \pi_{r(H I D)} / \partial P_{r}{ }^{2} & \partial^{2} \pi_{r(H I D)} / \partial P_{r} P_{d} \\ \partial^{2} \pi_{r(H I D)} / \partial P_{d} P_{r} & \partial^{2} \pi_{r(H I D)} / \partial P_{d}{ }^{2}\end{array}\right]=\left[\begin{array}{cc}-2 \alpha_{1} & \beta_{1}+\beta_{2} \\ \beta_{1}+\beta_{2} & -2 \alpha_{2}\end{array}\right]$

Similar answers are obtained as in Appendix B. Thus, $\pi_{r(H I D)}$ is strictly concave in $P_{r}$ and $P_{d}$.

Consequently second derivative of $\pi_{m \text { (HID) }}$ with respect to $W$ is given by

$$
\begin{gathered}
\partial^{2} \pi_{r(H I D)} / \partial W^{2}=\frac{2 \beta_{1} B 3}{B 1}-\frac{2 \alpha_{2} B 3}{B 1}-\frac{2 \alpha_{1} B 2}{B 1}+\frac{2 \beta_{2} B 2}{B 1}<0 . \text { Thus, } \pi_{m(H I D)} \text { is strictly concave in } W . \\
B 1=t\left(\beta_{1}{ }^{2}+2 \beta_{1} \beta_{2}+\beta_{2}{ }^{2}-4 \alpha_{1} \alpha_{2}\right) \\
B 2=t\left(\beta_{1}{ }^{2}-2 \alpha_{1} \alpha_{2}-\alpha_{2} \beta_{1}+\alpha_{2} \beta_{2}+\beta_{1} \beta_{2}\right) \\
B 2=t\left(\beta_{2}{ }^{2}-2 \alpha_{1} \alpha_{2}+\alpha_{1} \beta_{1}-\alpha_{1} \beta_{2}+\beta_{1} \beta_{2}\right)
\end{gathered}
$$

